\title{
Visualization of Synaptic Inhibition with an Optogenetic Sensor Developed by Cell-Free Protein Engineering Automation
}

\author{
Joshua S. Grimley, ${ }^{1 \star}$ Li Li, ${ }^{2 \star}$ Weina Wang,,${ }^{1}$ Lei Wen, ${ }^{3}$ Lorena S. Beese, ${ }^{1}$ Homme W. Hellinga, ${ }^{1}$ \\ and George J. Augustine ${ }^{2,3,4,5,6}$ \\ ${ }^{1}$ Department of Biochemistry and ${ }^{2}$ Department of Neurobiology, Duke University Medical Center, Durham, North Carolina 27710, ${ }^{3}$ Center for Functional \\ Connectomics, Korea Institute of Science and Technology, Seongbukgu, Seoul, 136-791 Republic of Korea, ${ }^{4}$ Program in Neuroscience and Behavioral \\ Disorders, Duke-NUS Graduate Medical School, Singapore 169857, Singapore, ${ }^{5} \mathrm{~A}^{\star S T A R / D u k e-N U S ~ N e u r o s c i e n c e ~ R e s e a r c h ~ P a r t n e r s h i p, ~ P r o t e o s, ~ S i n g a p o r e ~}$ \\ 138673, Singapore, ${ }^{6}$ Lee Kong Chian School of Medicine, Nanyang Technological University, Singapore 637553, Singapore, and ${ }^{7}$ Institute of Molecular and \\ Cell Biology, Singapore 138673, Singapore
}

We describe an engineered fluorescent optogenetic sensor, SuperClomeleon, that robustly detects inhibitory synaptic activity in single, cultured mouse neurons by reporting intracellular chloride changes produced by exogenous GABA or inhibitory synaptic activity. Using a cell-free protein engineering automation methodology that bypasses gene cloning, we iteratively constructed, produced, and assayed hundreds of mutations in binding-site residues to identify improvements in Clomeleon, a first-generation, suboptimal sensor. Structural analysis revealed that these improvements involve halide contacts and distant side chain rearrangements. The development of optogenetic sensors that respond to neural activity enables cellular tracking of neural activity using optical, rather than electrophysiological, signals. Construction of such sensors using in vitro protein engineering establishes a powerful approach for developing new probes for brain imaging.

\section{Introduction}

Optogenetic sensors (OSs) based on the green fluorescent protein (GFP), combined with advances in optical imaging methods, have enabled quantitative monitoring of cellular processes with high spatiotemporal resolution (Okumoto, 2010). Many such OSs have been developed to track subcellular localization (Flach et al., 1994) or monitor protein-protein interactions (Xia et al., 2001), and have great potential for measurement of neuronal activity by enabling precise, cellular-level reporting of neural circuit activity (Zhang et al., 2010; Mancuso et al., 2011) based on optical rather than electrophysiological signals (Siegel and Isacoff, 1997; Kuner and Augustine, 2000; Hires et al., 2008). However, engineering OSs that monitor the small and rapid

Received Sept. 9, 2011; revised Aug. 14, 2013; accepted Sept. 5, 2013.

Author contributions: J.S.G., L.L., W.W., L.W., L.S.B., H.W.H., and G.J.A. designed research; J.S.G., L.L., W.W., and L.W. performed research; J.S.G., L.L., W.W., L.W., L.S.B., H.W.H., and G.J.A. analyzed data; J.S.G., L.L., W.W., L.W., L.S.B., H.W.H., and G.J.A. wrote the paper.

This work was supported by the Duke Institute for Brain Science and the National Institutes of Health Director's Pioneer Award (5DPI 0D000122), by a Competitive Research Program grant from the National Research Foundation (NRF) of Singapore, and by the World Class Institute Program of the NRF of Korea funded by the Ministry of Education, Science, and Technology of Korea (NRF Grant number WCI 2009-003). We thank Ken Berglund for many helpful discussions.

*J.S.G. and L.L. contributed equally to this work.

The authors declare no competing financial interests.

Correspondence should be addressed to either of the following: Homme Hellinga, Department of Biochemistry, Duke University Medical Center, P.0. Box 3711, Durham, NC 27710, E-mail: hwh@biochem.duke.edu; or George Augustine, Lee Kong Chian School of Medicine, Nanyang Technological University, Singapore 637553, Singapore, E-mail: georgea@neuro.duke.edu.

J.S. Grimley's present address: Allen Institute for Brain Science, Seattle, WA 98103.

DOI:10.1523/JNEUROSCI.4616-11.2013

Copyright $\odot 2013$ the authors $\quad 0270-6474 / 13 / 3316297-13 \$ 15.00 / 0$ changes in the concentrations of signaling molecules typically associated with neuronal activity has been challenging (Miyawaki et al., 1997; Kuner and Augustine, 2000; Okumoto et al., 2005; Hires et al., 2008; Arosio et al., 2010).

Presynaptic release of GABA opens postsynaptic GABA receptors, resulting in $\mathrm{Cl}^{-}$fluxes that underlie synaptic inhibition. Fluorescent OSs that monitor intracellular $\mathrm{Cl}^{-}$concentration, $\left[\mathrm{Cl}^{-}\right]_{\mathrm{i}}$, therefore could report on this important class of synaptic action. A first-generation $\mathrm{Cl}^{-}$sensor, Clomeleon, has been used to monitor such dynamic changes in $\left[\mathrm{Cl}^{-}\right]_{\mathrm{i}}$ in cultured neurons (Kuner and Augustine, 2000) and in brain tissue (Berglund et al., 2006). Clomeleon is a fusion of the yellow fluorescent protein (YFP), which contains a serendipitous $\mathrm{Cl}^{-}$binding site adjacent to its chromophore (Wachter et al., 2000), and the chlorideinsensitive cyan fluorescent protein (CFP). Halide binding to YFP quenches fluorescence emission (Wachter and Remington, 1999), altering fluorescence resonance energy transfer (FRET) between the CFP donor and the YFP acceptor (Kuner and Augustine, 2000). The use of FRET enables ratiometric determination of $\left[\mathrm{Cl}^{-}\right]_{\mathrm{i}}$, which is unaffected by variations in fluorescence emission intensity associated with differences in indicator concentration, optical path length, or excitation intensity (Bright et al., 1989; Miyawaki, 2005). However, it remains extremely challenging to detect GABA-induced $\left[\mathrm{Cl}^{-}\right]_{\mathrm{i}}$ changes with Clomeleon because the $\mathrm{Cl}^{-}$affinity of Clomeleon $(\sim 100 \mathrm{~mm})$ is well beyond the physiological range of $\left[\mathrm{Cl}^{-}\right]_{\mathrm{i}}(\sim 5-6 \mathrm{~mm}$ in most adult neurons; Berglund et al., 2006). This limits the signal-to-noise ratio $(\mathrm{s} / \mathrm{n})$, requiring averaging of multiple trials before a response can be detected via fluorescence imaging. 
Here we report the use of recently developed protein engineering automation techniques (Cox et al., 2007; Allert et al., 2010) to improve the fluorescence response of Clomeleon by manipulating its halide affinity and fluorophore characteristics. The resulting sensor, SuperClomeleon, has a significantly improved $s / n$ in the relevant range of postsynaptic $\left[\mathrm{Cl}^{-}\right]_{\mathrm{i}}$ and greatly enhances imaging of synaptic inhibition in neurons.

\section{Materials and Methods}

Protein engineering. Oligonucleotides ( $79-80$ bases) were synthesized by solid phase oligonucleotide synthesis (MerMade 192; BioAutomation) and assembled into full-length open reading frames (ORFs) by automation (Cox et al., 2007), which were reamplified by PCR using 5'biotinylated primers.

Protein was produced by in vitro-coupled transcription and translation (TnT) reactions (Allert et al., 2010): $2.4 \mu \mathrm{g}$ of linear, biotinylated dsDNA was added to $30 \mu \mathrm{l}$ of a BL21 Star (DE3; Invitrogen) cell lysate and a solution of amino acids, nucleotide triphosphates, and cofactors and water (final volume $120 \mu \mathrm{l}$ ) in 96-well PCR plates, which were covered with a breathable seal for optimum aerobic expression and chromophore maturation (Heim et al., 1994), and incubated with shaking for $8 \mathrm{~h}$ at $30^{\circ} \mathrm{C}$, followed by $6 \mathrm{~h}$ at $4^{\circ} \mathrm{C}$.

All proteins had combined C-terminal Flag and $\mathrm{His}_{6}$ peptides for affinity purification. Proteins were purified at $4^{\circ} \mathrm{C}$ from $\mathrm{TnT}$ reactions using anti-Flag M2 agarose (Sigma) and $\mathrm{Cl}^{-}$-free buffer: four (15 min) washes of agarose-bound FPs with 20 mM HEPES, pH 7.1, removed $\mathrm{Cl}^{-}$ before elution with $120 \mu \mathrm{l}$ of $3 \times$ Flag (Sigma). Protein expression and purity relative to a sample of the Clomeleon chloride-sensitive YFP Topaz domain (CT) was determined by densitometry of the YFP band in protein gels stained with GelCode Blue (Thermo Scientific) using ImageJ (release 1.42q) software (good category of expression $>90 \%$ pure; poorly expressed proteins were less pure). Protein expression levels neither indicated nor predicted fluorescence brightness, although high fluorescence was correlated with good protein expression.

The linear ORF of CT was optimized for improved expression in Escherichia coli (Allert et al., 2010) is as follows: $5^{\prime}$-CGGCGTAGAGGATCGAGA TCTCGATCCCGCGAAATTAATACGACTCACTATAGGGGAATTGTGA GCGGATAACAATTCCCCTCTAGAAATAATTTTGTTTAACTTTAAGA AGGAGATATACCATGGTTAGCAAAGGAGAAGAATTATTTACAGGC GTTGTTCCTATATTAGTAGAATTAGATGGAGACGTAAATGGTCAT AAATTCAGCGTATCGGGTGAAGGTGAAGGTGACGCAACCTATGG CAAACTGACCCTGAAATTCATCTGCACCACCGGCAAATTACCAGT ACCATGGCCGACCTTAGTAACCACCTTCGGATACGGCGTCCAATG CTTCGCTCGTTATCCGGATCACATGCGTCAGCACGACTTCTTTAA AAGCGCCATGCCGGAAGGCTATGTACAGGAACGCACGATCTTCT TCAAAGACGACGGCAACTACAAAACCCGTGCGGAAGTGAAATTC GAAGGCGATACCCTGGTAAACCGCATCGAACTGAAAGGCATAGA CTTCAAAGAAGACGGCAACATCCTGGGCCACAAACTGGAATACAA CTACAACAGCCACAACGTCTACATCATGGCGGACAAACAGAAAAA CGGCATCAAGGTGAACTTCAAAATCCGCCACAACATCGAAGATGG CAGCGTACAACTGGCGGATCACTATCAGCAGAATACCCCAATCG GCGATGGTCCAGTTCTGCTTCCGGATAACCACTACCTGAGCTATC AGAGCGCACTGAGCAAAGATCCGAACGAAAAACGCGATCACATGGT GCTCCTGGAATTCGTAACCGCAGCAGGCATTACCTTAGGCATGGAC GAACTGTACAAAGGCGGCAGCAACGATTACAAAGACGACGACGATA AAGGCGGTAGCCATCATCACCACCACCACTAATAAGAGATCCGGCT GCTAACAAAGCCCGAAAGGAAGCTGAGTTGGCTGCTGCCACCGCTGA GCAATAACTAGCATAACCCCTTGGGGCCTCTAAACGGGTCTTGAGG$3^{\prime}$, where the italicized portions highlight the regulatory elements before and after the gene. CT is the FRET acceptor in Clomeleon (Kuner and Augustine, 2000) and includes Val1a, L68V, K79R, R80Q, Q148H, and H231L mutations relative to the YFP used to identify halide-binding Site I (Wachter et al., 2000).

The protein sequences of CFP and YFP from Clomeleon were 95\% identical. To favor unique sites for primer annealing, the CFP DNA sequence was diverged from YFP to only $79 \%$ identity. CFP ORFs, assembled in the manner described above, encoded the C-terminal 24 aa linker and the AgeI restriction site of Clomeleon (Kuner and Augustine, 2000), but with a scrambled rTEV sequence of FQENLY. The diverged DNA sequence of Clomeleon CFP is as follows: $5^{\prime}$-ATGGTAAGCAAAGGTGAAGAACTGTTCA CGGGCGTTGTCCCGATTTTGGTTGAACTCGATGGTGATGTTAATG GTCACCGTTTTTCTGTCAGCGGCGAGGGTGAAGGTGATGCCACCT ACGGTAAACTGACCTTGAAATTTATTTGCACGACCGGCAAACTGC CGGTTCCATGGCCGACGTTGGTCACCACGCTGACCTGGGGTGTTC AATGCTTTTCTCGCTACCCGGATCACATGAAACAGCATGACTTTTT CAAGTCCGCCATGCCGGAAGGTTATGTGCAGGAACGCACCATCT TTTTCAAAGATGACGGCAACTACAAGACCCGTGCTGAAGTCAAGT TTGAAGGTGATACCTTGGTTAATCGTATCGAGCTGAAAGGTATTG ATTTTAAAGAAGATGGCAACATTCTGGGTCACAAACTGGAATACA ACTATATCAGCCACAATGTTTACATCACCGCAGACAAACAAAAGA ATGGCATCAAAGCGCATTTCAAAATTCGCCACAACATTGAAGATG GTAGCGTTCAACTGGCGGACCATTATCAACAAAATACGCCAATTG GCGATGGCCCGGTCTTGCTGCCGGACAACCATTACCTGTCCACC CAATCTGCCCTCTCGAAAGATCCGAACGAAAAGCGTGACCAvCAT GGTCTTGCTGGAGTTTGTGACCGCAGCGGGCATTACACATGGCA TGGATGAACTGTACAAAAAGCTCACCGGTTCGGGCTCGGGTTTTC AGAACGAACTCTATGGTGGCGGCTCCGGCGGTACTAGCTCGACCG GCGGCAGCAACGATTACAAAGACGACGACGATAAAGGCGGTAGC CATCATCACCACCACCAC- 3 ' , where the 72 italicized bases correspond to the 24 aa linker.

The linear DNA ORFs of select variants were amplified with primers to clone each ORF into the BamHI (5'-CGCGGATCCCGGCGTAGAGGAT CGAGATCTCGATCCC-3') and HindIII ( $5^{\prime}$-CCCAAGCTTCCTCAAGAC CCGTTTAGAGGCCCCAAGG-3') restriction sites of pUC19 (Invitrogen). For the gene fusions encoding the 24 aa linker, the CFP vector was digested with AgeI and HindIII. The YFP genes were amplified from their vectors with the $3^{\prime}$ HindIII primer and a new $5^{\prime}$ primer (5'-AAGCTCACCGGTTC GGGCTCGGGTTTTCAGAACGAACTCTATGGTGGCGGCTCCGGCG GTACTAGCTCGACCATGGTTAGCAAAGGAGAAGAATTATTTACA G-3') encoding the linker and AgeI site.

Truncated fusions connected by the two-residue linker were accessed from either the 24 aa-linked fusions or the individual FP clones. Sitedirected mutagenesis ( $5^{\prime}$-GAGTTTGTGACCGCAGCGCTCGAGGAAG AATTATTTACAGGC- $3^{\prime}$ and its reverse complement) provided direct replacement of 40 aa (11 C-terminal donor, 24 linker, and $5 \mathrm{~N}$-terminal acceptor) with the two-residue Leu-Glu (XhoI site) linker (Shimozono et al., 2006).

CT variants were titrated with halide under ambient conditions in 384-well microtiter plates (Corning 3821) using a fluorescence plate reader (Tecan Genios) with appropriate excitation $(485 \pm 10 \mathrm{~nm})$ and emission $(535 \pm 12.5 \mathrm{~nm})$ filters. Constant ionic strength (screen, 520 $\mathrm{mm}$; conventionally prepared, $146 \mathrm{~mm}$ ) was maintained with potassium D-gluconate (Wachter and Remington, 1999)containing the following: 20 mM buffer (KOAc, pH 4.0, 5.0; MES, pH 5.5, 6.0, 6.5; HEPES, pH 7.1, 7.5; TAPS $\mathrm{pH}$ 8.0; CHES, $\mathrm{pH} 9.0$; CAPS, $\mathrm{pH}$ 10.0; $\mathrm{pH}$ adjusted with $\mathrm{KOH}$ and $\mathrm{HOAc}$ ). The in vitro screen used proteins purified from $\mathrm{TnT}$ reactions, $\mathrm{KCl}$ buffers ( $0-500 \mathrm{~mm}$; $\mathrm{pH} 7.1,0.1 \%$ bovine serum albumin), and $150 \mathrm{~mm}$ KF buffer for endpoint determination of fully quenched fluorescence emission intensity. Titrations of conventionally prepared CT variants $(5 \mu \mathrm{M}$ dialyzed protein diluted to $1 \mu \mathrm{M}$ with $20 \mathrm{~mm}$ buffer, $150 \mathrm{mM}$ ionic strength) used 14 potassium halide buffers $(0-108 \mathrm{~mm})$ and a 108 $\mathrm{mm} \mathrm{KF}$ endpoint buffer (four replicates per data point).

For conventional protein expression and purification, the pUC19 FP recombinants were transformed into KRX cells (Promega) and expressed in ZYM-5052 auto-induction media (Studier, 2005) with the T7 RNA polymerase under the control of the rhamnose promoter. Cultures were grown in shaker flasks at $25^{\circ} \mathrm{C}$ for up to $24 \mathrm{~h}$. Proteins were purified (>95\% pure) using nickel-charged immobilized ion affinity chromatographic (IMAC) beaded agarose and eluted into $50 \mathrm{~mm}$ sodium phosphate, $300 \mathrm{~mm} \mathrm{NaCl}$, and $300 \mathrm{~mm}$ imidazole at $\mathrm{pH} 7.8$. Bound $\mathrm{Cl}^{-}$was removed by five rounds of 1:1000 dialysis with $10 \mathrm{kDa}$ cutoff membranes in $20 \mathrm{~mm}$ HEPES, $\mathrm{pH} 7.1$, at $4^{\circ} \mathrm{C}$. The single domain YFP variants were stable at $4^{\circ} \mathrm{C}$ for months. The CFP-YFP fusions were stored stably at $4^{\circ} \mathrm{C}$ for up to 1 week or flash frozen in liquid nitrogen for prolonged storage at $-80^{\circ} \mathrm{C}$. Fusion proteins were titrated with $\mathrm{Cl}^{-}$in triplicate in a spectrofluorometer (SLM Aminco-Bowman series 2; Spectronic Instru- 
ments): $25^{\circ} \mathrm{C}, 4 \mathrm{ml}$ quartz cuvettes, exciting at $450 \pm 1 \mathrm{~nm}$, collecting emission spectra ( $460-550 \mathrm{~nm}$ ), and $4 \mathrm{~nm}$ slit widths.

Thermal stabilities were measured following fluorescence emission intensities in a real-time PCR instrument (LightCycler 480 II; Roche), 384 -well microtiter plates, heating at $1.1^{\circ} \mathrm{C} / \mathrm{min}\left(20-95^{\circ} \mathrm{C}\right), 10$ acquisitions $/{ }^{\circ} \mathrm{C}, 1 \mathrm{~s}$ integration time, and a $498 \pm 40 \mathrm{~nm}$ excitation filter and $580 \pm 20 \mathrm{~nm}$ emission filter. The denaturation transition midpoint temperature $\left(T_{\mathrm{m}}\right)$ values were obtained from first-derivative transforms of the data. Conventionally cloned and expressed single-domain Q69T/ V163A variant (79.7 $\mu \mathrm{M}$ in $20 \mathrm{~mm}$ HEPES, $\mathrm{pH}$ 7.1) was diluted to $3 \mu \mathrm{M}$ in $2 \mathrm{ml}$ of $20 \mathrm{~mm}$ MES, pH 6.0, in a quartz cuvette with a Teflon-coated stir bar and stopper. Coincidence of thermal melts monitored by fluorescence and by circular dichroism (CD) was determined using an Aviv model 202 $\mathrm{CD}$ spectrophotometer, the sample was heated $20-98^{\circ} \mathrm{C}$ while simultaneously monitoring the $\mathrm{CD}(222 \mathrm{~nm})$ and fluorescence (513 nm excitation monochromator and $530 \mathrm{~nm}$ Schott high-pass filter) signals.

Changes in error, $\delta S / S$ (Marvin et al., 1997), of variant $i$ relative to a reference species, ref, at the midpoint of analyte fluctuations, $S_{M}$, can be defined as follows:

$$
\rho_{M}=\frac{\left(\frac{\delta S}{S}\right)_{r e f}}{\left(\frac{\delta S}{S}\right)_{i}}=\left(\frac{S_{M}+K_{d, r e f}}{S_{M}+K_{d, i}}\right)^{2} \cdot \frac{K_{d, i} \cdot \Delta F_{\text {max }, i}}{K_{d, r e f} \cdot \Delta F_{\text {max }, r e f}}
$$

where $32 \rho_{\mathrm{M}}>1$ for improved variants (for $\left[\mathrm{Cl}^{-}\right]_{\mathrm{i}}$ sensing, the midpoint, $M$, is $5.5 \mathrm{~mm}$ ).

$X$-ray crystallography. The Q69T/V163A variant was purified by IMAC (see above), followed by gel filtration (Superdex200; GE Healthcare), eluting with $50 \mathrm{~mm}$ Tris and $150 \mathrm{~mm} \mathrm{NaCl}, \mathrm{pH}$ 7.5. The protein was concentrated, dialyzed, spin concentrated ( $10 \mathrm{kDa}$ cutoff; Sartorius) to $16.4 \mathrm{mg} / \mathrm{ml}$, and crystallized in hanging drops: $2 \mu \mathrm{l}$ of protein, $2 \mu \mathrm{l}$ of mother liquor (either 21\% (w/v) PEG 2K, 50 mM NaOAcat, pH 4.6, 90 mм $\mathrm{MgCl}_{2}$; or $10 \% \mathrm{PEG} 3 \mathrm{~K}, 150 \mathrm{~mm} \mathrm{NH}_{4} \mathrm{OAc}$ at $\mathrm{pH} 5.4$ ) for $3 \mathrm{~d}$ at $17^{\circ} \mathrm{C}$. The crystals were transferred to cryoprotectant (22\% PEG $2 \mathrm{~K}, 50 \mathrm{~mm}$ $\mathrm{NaOAc}$ at $\mathrm{pH} 4.6$ ) with $20 \%$ ethylene glycol and either water (apo) or 100 mм KI (Wachter et al., 2000), equilibrated at room temperature (2 h), and flash frozen in liquid nitrogen. X-ray diffraction data were collected at the Advanced Light Source SIBYLS beam line at $1.1109 \AA$ (apo, 3ST0) and $1.1169 \AA$ (iodide, 3 SV5). The diffraction images were processed using HKL2000 (Otwinowski and Minor, 1997). The crystal structure was solved by molecular replacement using Phaser (McCoy et al., 2007) and the YFP structure $2 \mathrm{O} 24$ (Arosio et al., 2007) as the search model. Initial model building and refinement was done in REFMAC (Murshudov et al., 1997), further refinement including ligand occupancy was performed in PHENIX (Adams et al., 2010), model rebuilding was done in Coot (Emsley and Cowtan, 2004), and figures were prepared using PyMOL (DeLano Scientific). Data collection at the SIBYLS beam line, Advanced Light Source, Lawrence Berkeley National Laboratory, was supported in part by the U.S. Department of Energy programs for Integrated Diffraction Analysis Technologies, Molecular Assemblies Genes, and Genomics Integrated Efficiently (Contract DE-AC02-05CH11231).

SuperClomeleon. The protein sequence of SuperClomeleon with the $\mathrm{C}$-terminal Flag and $\mathrm{His}_{6}$ epitope tags (italicized) used in the in vitro assays was as follows:

MVSKGEELFTGVVPILVELDGDVNGHKFSVRGEGEGDATYGKLTL KFICTTGKLPVPWPTLVTTLTWGVQCFARYPDHMKQHDFFKSAMP EGYVQERTIFFKDDGNYKTRAEVKFEGDTLVNRIELKGIDFKEDGNIL GHKLEYNAISDNVYITADKQKNGIKANFKIRHNIEDGSVQLADHYQ QNTPIGDGPVLLPDNHYLSTQSALSKDPNEKRDHMVLLEFVTAALEE ELFTGVVPILVELDGDVNGHKFSVRGEGEGDATYGKLTLKFICTTGKL PVPWPTLVTTFGYGVTCFARYPDHMRQHDFFKSAMPEGYVQERTIFF KDDGNYKTRAEVKFEGDTLVNRIELKGIDFKEDGNILGHKLEYNYNSH NVYIMADKQKNGIKANFKIRHNIEDGSVQLADHYQQNTPIGDGPVLLP DNHYLSYQSALSKDPNEKRDHMVLLEFVTAAGITLGMDELYKGGSNDY KDDDDKGGSHHHHHH.

Fusion constructs for eukaryotic expression. The C-terminal truncated CFP of Clomeleon was subcloned from pECFP (R26K, H164N, and
H231L relative to Clomeleon CFP; Clontech) by a sense primer containing a NheI site (5'-GTCAGATCCGCTAGCGCTAC-3') and an antisense primer containing an XhoI site (5'-AATAACTCGAGGGCGGCGGTCA CGAAC-3'). The N-terminal truncated YFP was subcloned from the pRK5-YFP vector by using a sense primer containing an XhoI site (5'CCACTCGAGGAGGAGCTGTTCACC- $3^{\prime}$ ) and an antisense primer containing an EcoRI site (5'-CGCGAATTCTATTAAAGCTTCTTGTA C- $3^{\prime}$ ). The original Clomeleon (Kuner and Augustine, 2000) was constructed in the mammalian expression vector pRK5. Removing the CFPcontaining portion by cutting and resealing at the SpeI site gave the pRK5-YFP vector. pECFP vector was cut open at the NheI and EcoRI site. The fragments encoding CFP and YFP were ligated into the NheI and EcoRI sites of pECFP. Mutations on YFP and CFP were performed by site-directed mutagenesis (Stratagene).

Cellular imaging. Neurons were obtained from cortex or hippocampus of postnatal day 0-2 mice (Mus musculus) of either sex and cultured according to standard procedures (Kuner and Augustine, 2000). Neurons were transfected 3-4 d after culturing, via Lipofectamine 2000 (Invitrogen; Gitler et al., 2004a).

OS FRET was imaged in the cell body of transfected neurons by using an upright two-photon microscope (Prairie Technology) equipped with a $60 \times$ water-immersion objective (Olympus), collecting fluorescence emission of CFP $(485 \pm 20 \mathrm{~nm})$ and YFP $(535 \pm 15 \mathrm{~nm})$ in parallel. The CFP donor was excited by $840 \mathrm{~nm}$ light from a Ti: sapphire laser (Chameleon; Coherent) with a Pockels cell to attenuate laser power. Images were acquired and analyzed with Prairie View software. Illumination and detection conditions were fixed for all measurements to facilitate comparisons between measurements made on different OSs. The experiments shown in Figure 9, $D-F$, were done similarly, but used an Olympus FV-1000 two-photon microscope with a $25 \times$ objective. It is important to note that the absolute values of FRET ratios depend on the acquisition conditions, such as photomultiplier gain and filter properties, and will therefore differ between microscopes.

To vary $\left[\mathrm{Cl}^{-}\right]_{\mathrm{i}}$, neurons (3-4 days in vitro) were transfected with OS variants, placed in a perfusion chamber, and treated with ionophores (10 $\mu \mathrm{M}$ nigericin and $5 \mu \mathrm{M}$ tributyltin acetate) to clamp $\left[\mathrm{Cl}^{-}\right]_{\mathrm{i}}$ and intracellular $\mathrm{pH}$ to extracellular levels. Physiological salines containing various $\left[\mathrm{Cl}^{-}\right]$were perfused through the chamber at a rate of $1 \mathrm{ml} / \mathrm{min}$. High$\left[\mathrm{Cl}^{-}\right]$saline contained $161 \mathrm{~mm} \mathrm{Cl}^{-}, 10 \mathrm{~mm}$ HEPES, $20 \mathrm{~mm} \mathrm{D}(+)$ glucose, $2 \mathrm{~mm} \mathrm{Na-EGTA}$, and $4 \mathrm{~mm} \mathrm{MgCl}_{2}$. $\mathrm{Cl}^{-}$-free saline consisted of $10 \mathrm{~mm}$ HEPES, $20 \mathrm{~mm} \mathrm{D}(+)$-glucose, $48 \mathrm{~mm} \mathrm{Na}$-gluconate, $105 \mathrm{~mm}$ $\mathrm{K}$-gluconate, $2 \mathrm{~mm} \mathrm{Na-EGTA}$, and $4 \mathrm{~mm} \mathrm{Mg}$ (gluconate) ${ }_{2}$. Intermediate $\left[\mathrm{Cl}^{-}\right]$solutions were prepared by mixing the two salines. The KF saline used to fully quench YFP fluorescence contained $10 \mathrm{~mm}$ HEPES, $20 \mathrm{~mm}$ $\mathrm{D}(+)$-glucose, $48 \mathrm{~mm} \mathrm{NaF}, 105 \mathrm{~mm} \mathrm{KF}, 2 \mathrm{~mm} \mathrm{Na-EGTA}$, and $4 \mathrm{~mm} \mathrm{Mg}$ (gluconate) ${ }_{2}$. All salines were adjusted to $\mathrm{pH} 7.1$.

Quantifying FRET measurements. FRET-based $\mathrm{Cl}^{-}$indicators such as Clomeleon and SuperClomeleon have emission spectra that change shape as a function of $\left[\mathrm{Cl}^{-}\right]$. These changes in the shape of the emission spectrum are quantified by measuring fluorescence emission at two wavelengths, $\lambda_{1}$ and $\lambda_{2}$, corresponding to the emission maxima for the CFP donor and YFP acceptor, respectively. An emission ratio, $R$, is then calculated from the fluorescence emission $(F)$ measured at these two wavelengths, $F_{1}$ and $F_{2}$ as follows:

$$
R=\frac{F_{2}}{F_{1}}
$$

$\mathrm{Cl}^{-}$decreases the fluorescence of the YFP acceptor, $F_{2}$. As a result, this ratio declines from a maximum, $R_{\max }$, in the absence of $\mathrm{Cl}^{-}$to a minimum, $R_{\min }$, in saturating $\left[\mathrm{Cl}^{-}\right]$. To convert the fluorescence emission ratio into $\left[\mathrm{Cl}^{-}\right]_{\mathrm{i}}$, the calibration scheme presented in Grynkiewicz et al. (1985) must be modified to take into account the fact that the titration curves decrease as a function of $\left[\mathrm{Cl}^{-}\right]$. Here we recapitulate the scheme of Grynkiewicz et al. (1985), in terms appropriate for measurement of $\left[\mathrm{Cl}^{-}\right]_{\mathrm{i}}$ by indicators such as Clomeleon and SuperClomeleon.

The starting point in this scheme is to state the fluorescence intensity at the two emission wavelengths in terms of four proportionality constants, $s$, representing the relative fluorescence of the $\mathrm{Cl}^{-}$bound (subscript $b$ ) 
and $\mathrm{Cl}^{-}$free (subscript $f$ ) forms of indicator at emission wavelengths $\lambda_{1}$ and $\lambda_{2}$. The total fluorescence of the indicator at each wavelength is then:

$$
\begin{aligned}
& F_{1}=S_{f_{1}} C_{f}+S_{b_{1}} C_{b} \\
& F_{2}=S_{f_{2}} C_{f}+S_{b_{2}} C_{b},
\end{aligned}
$$

where $c$ indicates the concentrations of the $\mathrm{Cl}^{-}$bound (subscript $b$ ) and $\mathrm{Cl}^{-}$-free (subscript $f$ ) species. $s_{\mathrm{f} 1}$ and $s_{\mathrm{b} 1}$ represent the fluorescence of the CFP donor in $\mathrm{Cl}^{-}$-free and saturating conditions, respectively. The relative fractions of the $\mathrm{Cl}^{-}$bound and $\mathrm{Cl}^{-}$-free forms of the indicator vary with $\left[\mathrm{Cl}^{-}\right]$according to the $\mathrm{Cl}^{-}$dissociation constant, $K_{\mathrm{d}}$, of the indicator:

$$
K_{d}=\frac{c_{f}}{c_{b}}\left(\left[C l^{-}\right]\right) .
$$

Combining Equations $3 \mathrm{a}$ and $\mathrm{b}$ allows $R$ to be expressed in terms of $s$ and $c$ :

$$
\mathrm{R}=\frac{\mathrm{s}_{\mathrm{f}_{2}} \mathrm{c}_{\mathrm{f}}+\mathrm{s}_{\mathrm{b}_{2}} \mathrm{c}_{\mathrm{b}}}{\mathrm{s}_{\mathrm{f}_{1}} \mathrm{c}_{\mathrm{f}}+\mathrm{s}_{\mathrm{b}_{1}} \mathrm{c}_{\mathrm{b}}}
$$

Combining Equations 4 and 5 then yields:

$$
R=\frac{s_{f_{2}}+\frac{s_{b_{2}}\left[\mathrm{Cl}^{-}\right]}{K_{d}}}{s_{f_{1}}+\frac{s_{b_{1}}\left[\mathrm{Cl}^{-}\right]}{K_{d}}} .
$$

This can be rearranged into the following expressions:

$$
\begin{gathered}
{\left[C l^{-}\right]\left(R s_{b_{1}}-s_{b_{2}}\right)=K_{d}\left(s_{f_{2}}-R s_{f_{1}}\right)} \\
{\left[C l^{-}\right]=K_{d} \frac{\left(\frac{s_{f_{2}}}{s_{f_{1}}}-R\right)\left(s_{f_{1}}\right)}{\left(R-\frac{s_{b_{2}}}{s_{b_{1}}}\right)\left(s_{b_{1}}\right)} .}
\end{gathered}
$$

The limiting values for the titration curve, $R_{\max }$ and $R_{\min }$, can be restated in terms of their component $s$ constants:

$$
\begin{gathered}
R_{\text {max }}=\frac{s_{f_{2}}}{s_{f_{1}}} \\
R_{\text {min }}=\frac{s_{b_{2}}}{s_{b_{1}}}
\end{gathered}
$$

Substituting these into Equation 8 yields:

$$
\left[C l^{-}\right]=K_{d}\left(\frac{R_{\max }-R}{R-R_{\min }}\right)\left(\frac{s_{f_{1}}}{s_{b_{1}}}\right) .
$$

Note that although the form of this equation closely resembles Equation 5 of Grynkiewicz et al. (1985), many of the terms are different.

It is worth emphasizing that while $K_{\mathrm{d}}$ is independent of the specific instrument used to measure $R$, all other variables on the right side of Equation 11 are instrument-specific. Thus, $R_{\max }, R_{\min }, s_{\mathrm{f} 1}$, and $s_{\mathrm{b} 1}$ must be determined empirically for each instrument used to measure $R$ for Clomeleon, SuperClomeleon, or other FRET-based $\mathrm{Cl}^{-}$indicators. This can be done by varying $\left[\mathrm{Cl}^{-}\right]_{\mathrm{i}}$ using the procedures described above.

Electrophysiology. Neurons were patch clamped via glass pipettes (5-6 $\mathrm{M} \Omega$ resistance) filled with an internal solution containing $5 \mathrm{mM} \mathrm{Cl}^{-}: 140$ mm K-gluconate, 10 mм HEPES, 4 mм Na-ATP, 0.4 mм Na-GTP, 5 mm EGTA, $0.5 \mathrm{~mm} \mathrm{CaCl}_{2}$, and $2 \mathrm{~mm} \mathrm{MgCl}_{2}$. Extracellular saline contained $150 \mathrm{~mm} \mathrm{NaCl}, 3 \mathrm{~mm} \mathrm{KCl}, 2 \mathrm{~mm} \mathrm{CaCl}$, $2 \mathrm{~mm} \mathrm{MgCl}_{2}, 20 \mathrm{~mm} \mathrm{D}(+)$-glucose, and $10 \mathrm{~mm}$ HEPES, pH 7.4. Electrophysiological signals were recorded using a Multiclamp 700B amplifier (Molecular Devices) and digitized with a Digidata 1440 (Molecular Devices) A-D converter. Data were
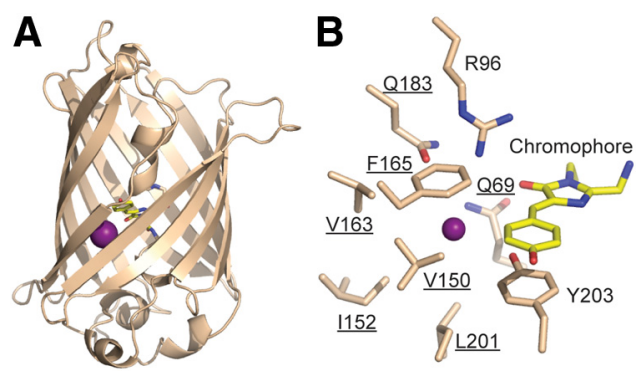

Figure 1. Iodide-binding site in YFP. $\boldsymbol{A}$, The structure of YFP (Wachter et al., 2000) with $\mathrm{I}^{-}$ (purple) in relation to the chromophore (yellow). $\boldsymbol{B}$, The iodide-binding site including residues selected for mutagenesis (underlined).

acquired and analyzed with pClamp10.1 software (Molecular Devices). GABA was locally applied onto neurons via pressure ejection. For this purpose, a glass pipette containing GABA (1 mM) was connected to a Picospritzer II (General Valve) to provide $100 \mathrm{~ms}$ pulses. IPSCs were evoked by stimulating presynaptic neurons using a concentric bipolar electrode (FHC). A train of extracellular current pulses $(75 \mu \mathrm{A}, 10 \mathrm{~Hz}$, $2 \mathrm{~s}$ ) were applied near the neuron being recorded from, while blocking EPSCs by adding $20 \mu \mathrm{M}$ CNQX and $50 \mu \mathrm{M}$ APV to the extracellular solution.

Throughout this paper, error determinations represent the SEM, unless indicated otherwise. Statistical comparisons were made with the Student's $t$ test (Press et al., 2007, p. 729).

\section{Results}

\section{Matching sensor affinity with $\left[\mathrm{Cl}^{-}\right]$}

Structural studies of YFP (Wachter et al., 2000; Griesbeck et al., 2001; Fig. 1A) have shown that its halide-binding site comprises the chromophore and nine nearby residues (Fig. 1B). The principles of molecular recognition determining halide binding are not well defined. Consequently, it is impossible to predict a priori how mutations in the halide-binding site contribute to binding affinity. We therefore used recently developed cell-free protein engineering methods (Cox et al., 2007; Allert et al., 2010) that bypass cloning steps (Fig. 2) to rapidly explore the $\mathrm{Cl}^{-}$binding and fluorescence properties of single, double, and triple mutants in the crystallographically defined halide-binding site. We mutated seven of these residues, avoiding Arg96, which catalyzes chromophore maturation (Barondeau et al., 2003; Sniegowski et al., 2005) and Tyr203, which tunes the spectral characteristics of YFP (Dickson et al., 1997). Starting with all 133 single mutants at these positions, double and triple mutations were iteratively constructed in CT in the absence of the CFP FRET donor (Kuner and Augustine, 2000). Another iterative set of mutants beginning with the 133 single mutations were also tested in CT H148Q, a mutation previously used to improve $\mathrm{Cl}^{-}$affinity (Jayaraman et al., 2000; Galietta et al., 2001; Markova et al., 2008) but with diminished fluorescence (Elsliger et al., 1999).

In noncooperative binding to a single site, changes in fluorescence emission intensity are directly proportional to the fraction of binding sites occupied by $\mathrm{Cl}^{-}(\bar{y})$. Sensor responses are maximal when the dissociation constant, $K_{\mathrm{d}}$, matches the midpoint of the relevant $\left[\mathrm{Cl}^{-}\right]_{\mathrm{i}}$ range (Marvin et al., 1997); in a mature neuron, $\left[\mathrm{Cl}^{-}\right]_{\mathrm{i}}$ rises from $\sim 5$ to $\sim 6 \mathrm{~mm}$ during synaptic inhibition (Berglund et al., 2006) with a midpoint of $5.5 \mathrm{~mm}$. For a singlesite hyperbolic binding isotherm, over such a range the theoretical maximal signal is $4.6 \%\left(K_{\mathrm{d}}=5.5 \mathrm{mM}, \Delta \bar{y}_{5,6}=\bar{y}_{6}-\bar{y}_{5}=\right.$ $0.046)$ of the difference in fluorescence intensities observed in the absence and saturating presence of $\mathrm{Cl}^{-}\left(\Delta F_{\max }\right)$. For Clomeleon $\left(K_{\mathrm{d}}=119 \mathrm{~mm}\right)$, the maximal signal is $0.8 \%$ of $\Delta F_{\text {max }}$; matching 


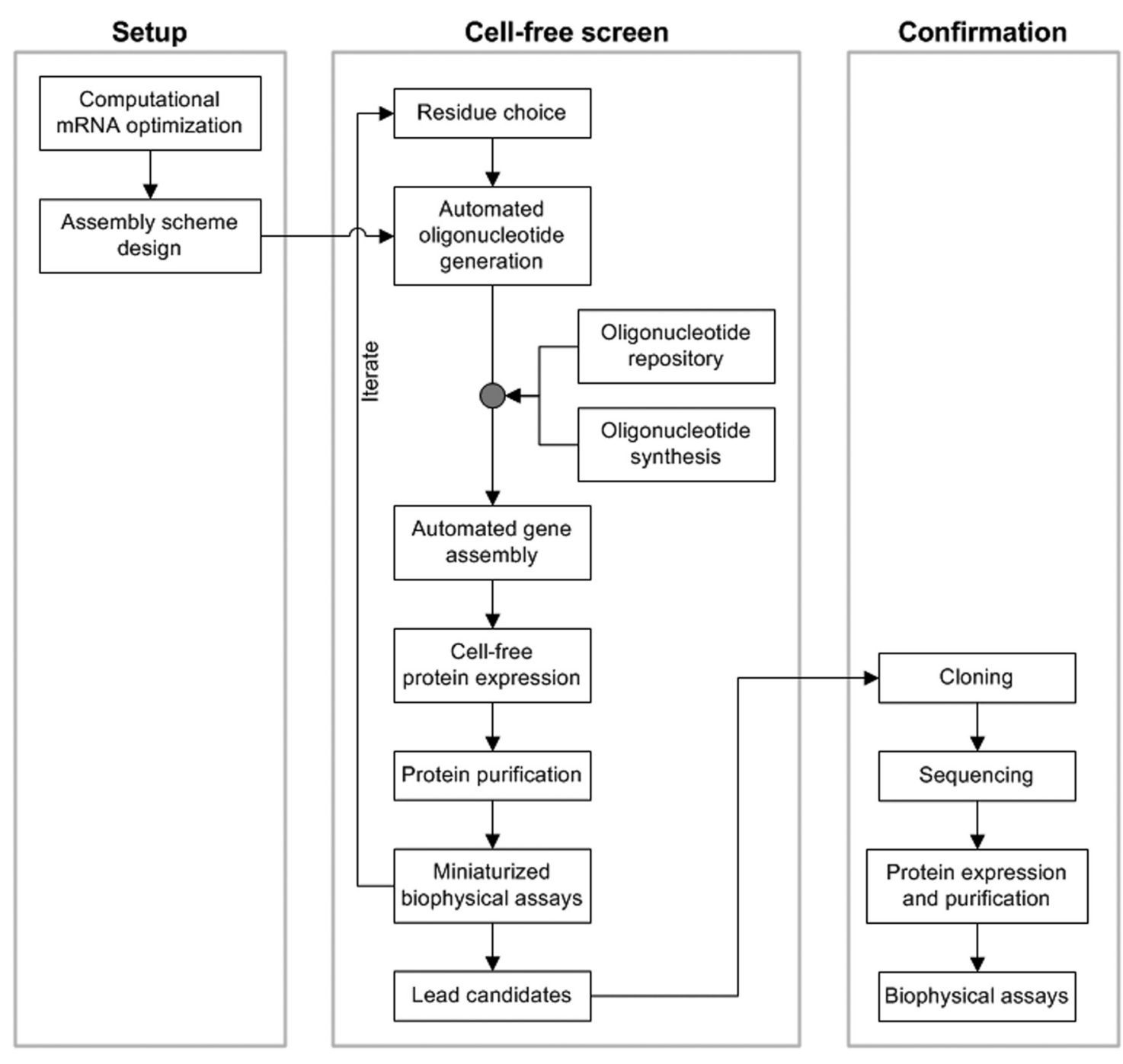

Figure 2. Protein engineering method.

$\mathrm{Cl}^{-}$affinity therefore could achieve a 5.9-fold improvement in signal, if $\Delta F_{\max }$ remained constant.

Clomeleon variants were rapidly screened using a cell-free protein engineering methodology that obviates cloning steps (Fig. 2). Linear DNA fragments encoded ORFs flanked by T7 RNA polymerase promoter and terminator sites were assembled robotically from synthetic oligonucleotides (Cox et al., 2007). The ORF mRNA sequence of CT was optimized computationally for E. coli expression (Allert et al., 2010). The resulting DNA fragments were then used to produce proteins by combined in vitro transcription and translation in $120 \mu \mathrm{l}$ aliquots of $E$. coli extracts, purified by small-scale affinity purification using beads, and assayed for $\mathrm{Cl}^{-}$binding in microtiter plates.

A total of 424 variants, encoded in genes constructed from 344 unique oligonucleotides, were tested in this manner. The genes encoding the initial 266 single-point mutants were assembled from 269 oligonucleotides. Following an initial triage of these single-point variants based on fluorescence and expression levels, the $\mathrm{Cl}^{-}$affinities of 131 variants were determined by $\mathrm{Cl}^{-}$titration using a fluorescence plate reader. Their response to $\mathrm{Cl}^{-}$was evaluated using a metric that takes into account both fluorescence and affinity matching, $\rho_{5.5}$. (see Materials and Methods) Twelve single mutants showed per- formance improvements $\left(\rho_{5.5}>1\right)$ with Q69T the only one having $\rho_{5.5}>2$ (Fig. $3 A, B$ ).

In subsequent assembly rounds, we constructed 150 double mutants from a subset of 29 single mutants and included single-point variant with $\rho_{5.5}<1$ to test whether improvements can arise by combining suboptimal intermediates. Out of these 150 double mutants, the five best $\left(\rho_{5.5} \geq 2.32\right)$ were combinations of only six single mutations (Q69T, V150A/I, and V163A/G/T), from which the set of all six possible triple mutants was constructed. With this automated gene assembly method, only 75 additional oligonucleotides were needed to construct the genes encoding the 156 higher-order mutants.

The average $K_{\mathrm{d}}$ values for $\mathrm{Cl}^{-}$binding of the 285 characterized CT variants improved from $101 \mathrm{~mm}$ (single) to $77.5 \mathrm{~mm}$ (double) to $33.3 \mathrm{~mm}$ (triple mutants), with a concomitant increase in average $\rho_{5.5}$ values from 0.43 to 0.83 to 2.21 . Based on their $\rho_{5.5}$ values, 63 variants $(22 \%)$ were improvements over CT (Fig. $3 B$ ) and had mutations in at least one of six binding site residues. The five highest affinity variants $\left(K_{\mathrm{d}}<10 \mathrm{~mm}\right)$ were single mutations at Gln183; these exhibited diminished fluorescence brightness and a reduced $\Delta F_{\max }$ response, precluding their use in cellular measurements (Fig. $3 A, B$ ). The 13 best variants had $\rho_{5.5}>2$ and included mutations at only three positions (Gln69, Val150, and Val163). The best CT mutant, Q69T/V163A, 

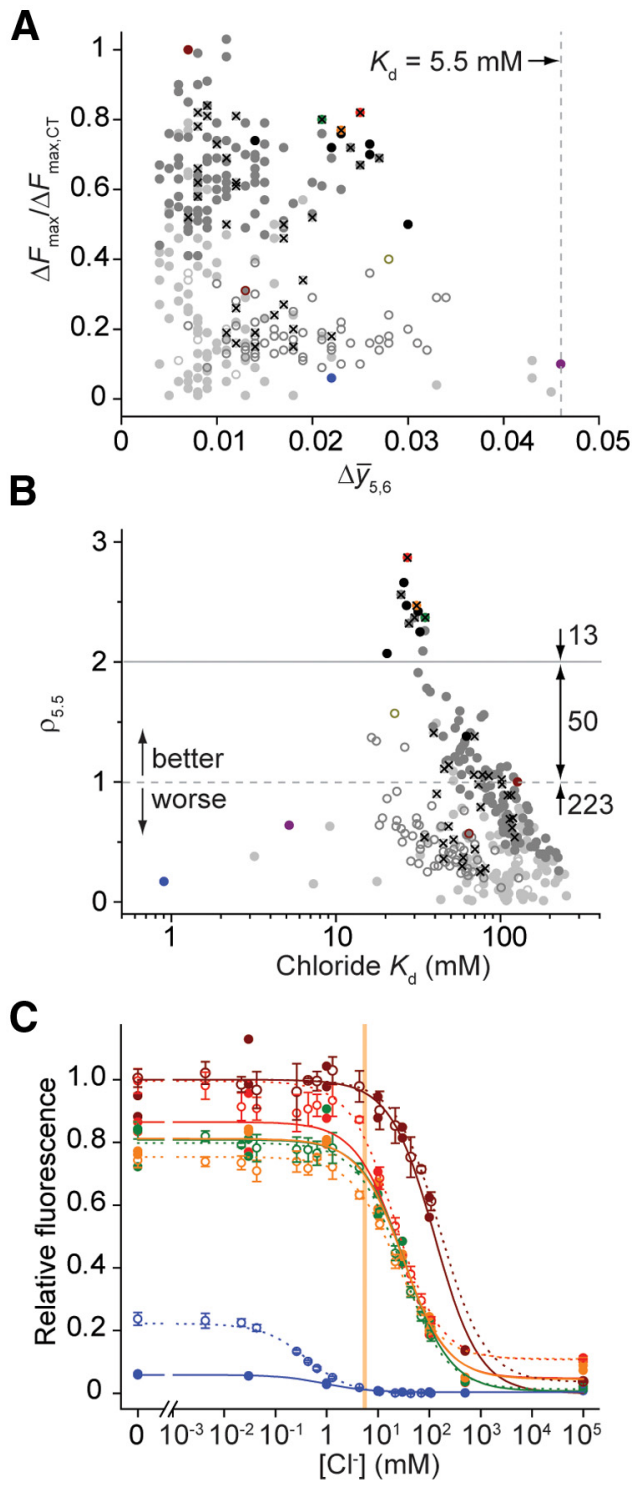

Figure 3. Chloride-binding properties of YFP variants. $A$, Performance assessment, correlating $\mathrm{Cl}^{-}$affinity matching $\left(\Delta \bar{y}_{5,6}\right)$ and $\Delta F_{\max }$ relative to $\mathrm{CT}\left(\Delta F_{\max , \mathrm{C} T}\right)$ : His 148 variants, open circles; His 1480 variants, closed circles; single mutants, light grey; double mutants, medium grey; triple mutants, black; $\mathrm{CT}$, dark red; $\mathrm{H1480}$, red open circle; $\mathrm{Q69T/}$ V163A, light red; Q69T, yellow; V150A/V163A, green; Q183A, blue; Q183G, magenta; H138Q/V163A/L201I, green open circle; single or double mutants that were subsequently included in higher order constructs, $X$. Vertical dashed line indicates a $K_{\mathrm{d}}$ of $5.5 \mathrm{~mm}$, at the midpoint of the $\left[\mathrm{Cl}^{-}\right]_{i}$ range of relevance for imaging synaptic inhibition in mature neurons. $\boldsymbol{B}$, Performance assessment, correlating values for the performance metric, $\rho_{5.5}$, with $\mathrm{Cl}^{-}$affinity. Distribution of mutants with decreased $\left(\rho_{5.5}<1\right)$, improved $\left(1<\rho_{5.5}\right.$ $<2)$, and superior $\left(\rho_{5.5}<2\right)$ performance is indicated. Colors and symbols as in $\mathrm{A} . \mathrm{C}_{,} \mathrm{Cl}^{-}$ titration of selected variants produced in vitro (filled circles, solid lines; no replicates) or by conventional expression (open circles, dashed lines; four replicates). Error bars indicate 1 SD. Fluorescence values are scaled to Clomeleon. Colors as in $\boldsymbol{A}$. Vertical bar indicates $\left[\mathrm{Cl}^{-}\right]_{i}$ between 5 and $6 \mathrm{~mm}$, the range of relevance for imaging synaptic inhibition in mature neurons.

was composed of individual single mutants each with $\rho_{5.5}>1$ and was almost three times more sensitive than CT in vitro (Table 1).

Using conventionally cloned and expressed protein, we assayed the binding and stability of 3 of the top 13 variants, as well as the original CT, the highest affinity variant Q183A, chloride-insensitive mutants Q69H and Q69M (Griesbeck et al., 2001), and four $\mathrm{H} 148 \mathrm{Q}$ variants. $\mathrm{Cl}^{-}$affinities were deter- mined by titration in a fluorescence plate reader. For most variants, the results were similar to the in vitro screening observations (Fig. 3C; Table 1). The $\mathrm{Cl}^{-}$dependence of thermal stabilities, which is thermodynamically linked to binding (Isom et al., 2010; Layton and Hellinga, 2010), was used to confirm the binding properties determined by titration. To determine thermal stabilities, the temperature dependence of the chromophore fluorescence was followed, which was coincident with the thermal stability determined by circular dichroism (Fig. $4 A$ ). $\mathrm{Cl}^{-}$increased the stability of chloride-responsive proteins, whereas the nonresponsive variants Q69H and Q69M showed minimal changes (Fig. $4 B$ ), consistent with the presence or absence of $\mathrm{Cl}^{-}$-binding sites inferred from fluorescence observations. No consistent trend in relative affinities for $\mathrm{F}^{-}, \mathrm{Br}^{-}$, and $\mathrm{I}^{-}$was observed (Table 1), indicating that molecular recognition of halides is quite complex (Wachter and Remington, 1999; Jayaraman et al., 2000; Kuner and Augustine, 2000). The pH dependence of fluorescence response and halide affinity (Fig. $5 A, B$ ) reveals linkage between chromophore ionization and binding affinity (see Discussion).

\section{Structural analysis}

High-resolution $\mathrm{x}$-ray structures of the halide-free (apo) and $\mathrm{I}^{-}$ complexes were determined for the Q69T/V163A variant that was used in cellular measurements (Fig. 6, Table 2). With the exception of some distant loops, the backbones of these two structures and YFP (Wachter et al., 2000) are essentially the same. Two $\mathrm{I}^{-}$sites were observed by anomalous scattering in the vicinity of the chromophore (Fig. 6A-E). One site (I) was observed previously (Wachter et al., 2000). The second site (II) is located 9 $\AA$ away, where $\mathrm{I}^{-}$replaces an interior water observed in the apoprotein. Small rearrangements of Thr63 and Thr108 side chains in the complex and apo-protein (Fig. $6 F$ ), relative to YFP, enable $\mathrm{I}^{-}$binding at Site II. The two side chain hydroxyls interact with the bound $\mathrm{I}^{-}$. Ethylene glycol (EG, used as cryoprotectant at 3.6 $\mathrm{M}$ in structure determination) also bound to Site I (Fig. 6C,E). Both $\mathrm{I}^{-}$and EG were observed at less than full occupancy in the complex, suggesting that these two ligands compete. EG binding neither was detectable by fluorescence quenching nor affected $\mathrm{Cl}^{-}$affinity and therefore EG is a low-affinity ligand. Formate was also observed to bind in the vicinity of the chromophore (Fig. $6 G)$; it is likely to originate from ultrafiltration membranes used in protein purification.

\section{FRET performance}

We fused the affinity-tuned CT variants with a CFP FRET donor to reconstruct improved versions of Clomeleon. The performance of these OSs was evaluated in vitro (Table 3 ) and in a series of cellular FRET measurements. The $\mathrm{Cl}^{-}$affinities of these sensors were determined by $\mathrm{Cl}^{-}$titration experiments (Fig. 7), using two-photon imaging to measure sensor FRET in the cell bodies of individual cultured hippocampal neurons transfected with the OS of interest (Fig. $7 A$ ). $\left[\mathrm{Cl}^{-}\right]_{\mathrm{i}}$ was varied by permeabilizing the cell membrane to external $\mathrm{Cl}^{-}$via ionophores (Berglund et al., 2006). The resulting changes in FRET emission (Fig. 7B) yielded titration curves such as those shown in Figure $7 C$. These curves were fit using Equation 11 to determine the $K_{\mathrm{d}}$ for $\mathrm{Cl}^{-}$binding. When imaging synaptic inhibition in neurons, the most important parameter is $\mathrm{s} / \mathrm{n}$. We therefore also estimated the $\mathrm{s} / \mathrm{n}$ for the novel OSs, using the approach described above: "signal" corresponded to the change in FRET as $\left[\mathrm{Cl}^{-}\right]_{\mathrm{i}}$ was raised from 5 to 6 $\mathrm{mM}$, and "noise" was the SD of the FRET ratio determined at 5 $\mathrm{mm}\left[\mathrm{Cl}^{-}\right]_{\mathrm{i}}$ for each cell. 
Table 1. Chloride binding to single domain YFP variants

\begin{tabular}{|c|c|c|c|c|c|c|c|c|c|}
\hline \multirow[b]{3}{*}{ YFP mutation } & \multirow{3}{*}{$\begin{array}{l}\text { Cell-free } \\
\mathrm{Cl}^{-} \text {screen } \\
\rho_{5.5}\end{array}$} & \multirow{2}{*}{\multicolumn{3}{|c|}{$\mathrm{Cl}^{-}$}} & \multicolumn{5}{|c|}{ Conventionally expressed protein } \\
\hline & & & & & \multirow{2}{*}{$\begin{array}{l}\mathrm{F}^{-} \\
K_{\mathrm{d}}(\mathrm{mm})\end{array}$} & \multirow{2}{*}{$\begin{array}{l}\mathrm{Br}^{-} \\
\mathrm{K}_{\mathrm{d}}(\mathrm{mm})\end{array}$} & \multirow{2}{*}{$\begin{array}{l}\mathrm{I}^{-} \\
K_{\mathrm{d}}(\mathrm{mm})\end{array}$} & \multirow[b]{2}{*}{$\mathrm{p} K_{\mathrm{a}}$} & \multirow[b]{2}{*}{$T_{\mathrm{m}}\left({ }^{\circ} \mathrm{C}\right)$} \\
\hline & & $\Delta F_{\max }^{a}$ & $K_{\mathrm{d}}(\mathrm{mm})$ & $\rho_{5.5}$ & & & & & \\
\hline Q69T/V163A & 2.87 & 0.92 & $21.2 \pm 2.2$ & 4.77 & $11.2 \pm 0.8^{b}$ & $33.3 \pm 1.7$ & $24.1 \pm 1.7$ & $6.4 \pm 0.1$ & $72.5 \pm 0.1$ \\
\hline Q69T & 2.47 & 0.67 & $21.0 \pm 1.2$ & 3.48 & $16.0 \pm 1.2^{b}$ & $53.2 \pm 3.2$ & $13.3 \pm 0.9^{b}$ & $6.3 \pm 0.1$ & $64.6 \pm 0.1$ \\
\hline V150A/V163A & 2.37 & 0.81 & $28.6 \pm 1.0$ & 3.48 & $1.09 \pm 0.02^{b}$ & $19.2 \pm 0.5$ & $12.4 \pm 0.3$ & $6.4 \pm 0.1$ & $67.3 \pm 0.1$ \\
\hline H1480 & 0.57 & 0.27 & $58.9 \pm 3.8$ & 0.67 & & & & $7.0 \pm 0.1$ & \\
\hline H148Q/V163S & 0.36 & 0.17 & $35.2 \pm 1.6$ & 0.62 & & & & & \\
\hline$Q 183 A^{b}$ & 0.17 & 0.23 & $0.417 \pm 0.030$ & 0.48 & $3.67 \pm 0.29$ & $0.272 \pm 0.014$ & $0.482 \pm 0.034$ & $6.7 \pm 0.1$ & $57.1 \pm 0.3$ \\
\hline $\mathrm{Q} 69 \mathrm{H}$ & \{ & & No response to $\mathrm{Cl}^{-}$ & & & & \} & $5.5 \pm 0.1$ & $73.4 \pm 0.1$ \\
\hline Q69M & \{ & & No response to $\mathrm{Cl}^{-}$ & & & & \} & $5.7 \pm 0.1$ & $73.7 \pm 0.1$ \\
\hline
\end{tabular}

Chloride binding to single domain YFP variants. All halide titration and thermal stability data determined at $\mathrm{pH}^{7.1 .}{ }^{a} \Delta F_{\max }$ values are scaled relative to Clomeleon Topaz. ${ }^{b}$ The $\mathrm{F}^{-}$endpoint was not included in the halide titration fits of conventionally prepared protein.
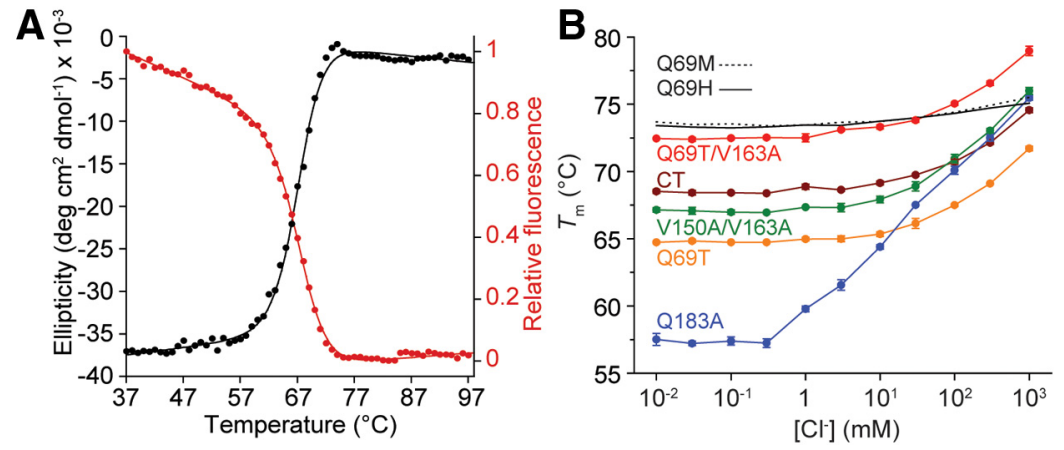

Figure 4. Thermal stabilities and their dependence on chloride binding. $A, 069 \mathrm{~T} / \mathrm{V} 163 \mathrm{~A} C \mathrm{CD}$ (black) and fluorescence (red) data acquired simultaneously at pH 6.0 and fit to a two-state unfolding mechanism. $T_{\mathrm{m}}$ values of $67.0 \pm 0.1^{\circ} \mathrm{C}(\mathrm{CD})$ and $67.2 \pm 0.1^{\circ} \mathrm{C}$ (fluorescence) differ with the entry in Table 1 due to differences in $\mathrm{pH}$, buffer, heating rate, and equipment. $\boldsymbol{B}$, The effect of $\mathrm{Cl}^{-}$ addition, pH7.1, on thermal stability (four replicates; error bars indicate 1 SD) of YFP variants. Q69H and Q69M data points and error bars removed for clarity.
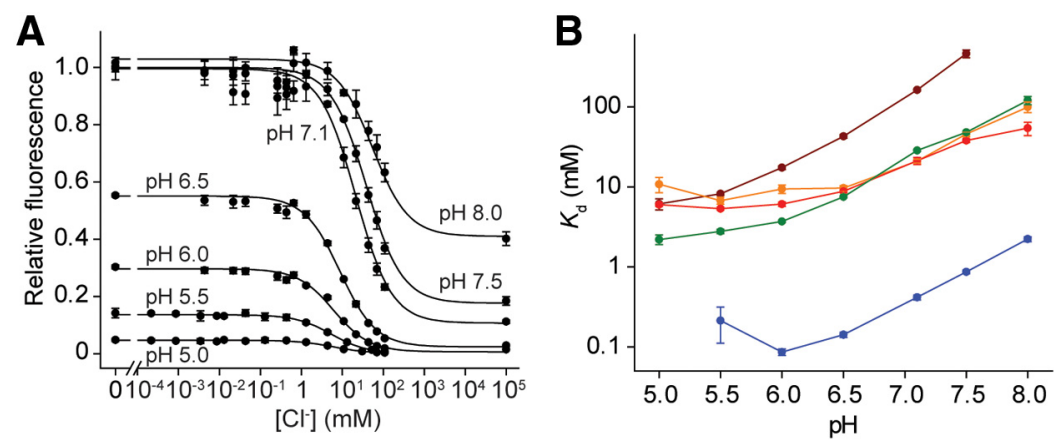

Figure 5. The effect of pH on chloride affinity. $\boldsymbol{A}$, Effect of $\mathrm{pH}$ on $\mathrm{Cl}^{-}$titrations illustrated for conventionally expressed Q69T/ V163A. Fluorescence emission is normalized relative to the amount of fluorescence measured at $\mathrm{pH} 7.1$ and in the absence of $\mathrm{Cl}^{-}$. $B$, The pH dependence of selected variants.

FRET depends upon both the distance between, and the orientation of, the fluorescent donor and acceptor. As a result, the linker between the donor and acceptor is an important determinant of FRET efficiency in GFP-based OSs (Evers et al., 2006). Therefore, to improve FRET efficiency, we used the strategy of Shimozono et al. (2006) to truncate the linker between the CFP and YFP of Clomeleon-based OSs: 40 residues (11 residues from the $\mathrm{C}$ terminus of CFP, the 24 -residue linker, and 5 residues from the $\mathrm{N}$ terminus of YFP) were replaced with two residues. This truncation (short linker) did increase FRET efficiency, evident as an increase in the difference in FRET ratios $\left(\Delta R_{\max }\right)$ observed in the absence of $\mathrm{Cl}^{-}$and in the presence of saturating concentrations of $\mathrm{Cl}^{-}$(or F${ }^{-}$; Fig. 7C). This version of Clomeleon exhibited enhanced $\mathrm{Cl}^{-}$binding affinity (Fig. 7C, inset) and improved s/n (Fig. 7D; $n=4)$. The mean $\mathrm{s} / \mathrm{n}$ measured for this version was significantly better than that of Clomeleon (Student's $t=52.1, p=0.000$ ).

Because donor and acceptor fluorescence also play important roles in determining $\mathrm{s} / \mathrm{n}$, we next introduced into both the donor and acceptor fluorophores a mutation (S30R) that increases brightness and stability (Pédelacq et al., 2006). This pair of mutations produced the largest improvement in $\Delta R_{\max }$ (Fig. $7 C$ ) and further improved s/n (Fig. $7 D ; n=18$ ), but had no effect on $\mathrm{Cl}^{-}$affinity (Fig. 7C, inset).

After making these improvements to the FRET properties of Clomeleon, we next replaced the YFP FRET acceptor with several affinity-tuned CT variants. All of these variants increased the $\mathrm{Cl}^{-}$affinity of Clomeleon: V163S (6.4 $\pm 0.4 \mathrm{~mm} ; n=8)$, I152L/V163A (4.8 $\pm 0.2 \mathrm{~mm} ; n=4)$, $\mathrm{V} 150 \mathrm{~A} / \mathrm{V} 163 \mathrm{~A}(4.6 \pm 0.2 \mathrm{mM} ; n=5)$, and V163A/L201I (2.5 $\pm 0.6 \mathrm{~mm} ; n=5)$. All of these also improved $\mathrm{s} / \mathrm{n}$ above that produced by the Clomeleon variant with the short linker and S30R mutations (Fig. 7D). We also tested an OS with YFP H148Q/I152L/V163S, a variant previously reported to have improved properties (Markova et al., 2008). However, for FRET-based measurements, this OS had $\mathrm{s} / \mathrm{n}$ properties no better than those of Clomeleon (Fig. 7D). This is due to its relatively poor $\mathrm{Cl}^{-}$affinity $(27.0 \pm 5.0 \mathrm{mM}$; $n=4)$ and the diminished fluorescence of the FRET acceptor (Table 1).

The largest improvement in $\mathrm{s} / \mathrm{n}$ was observed when the affinity-tuning mutations in the best $\mathrm{CT}$ variant from the cell-free screen, Q69T/V163A, were included in the OS FRET acceptor. 


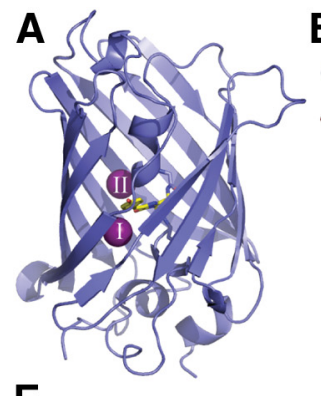

E

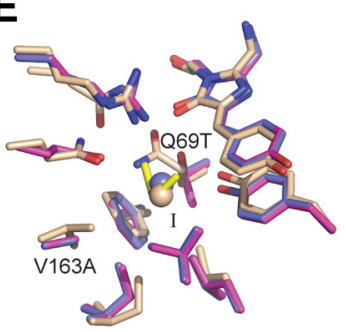

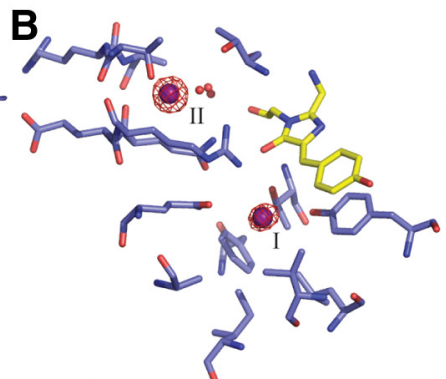

$\mathbf{F}$

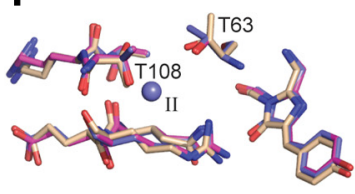

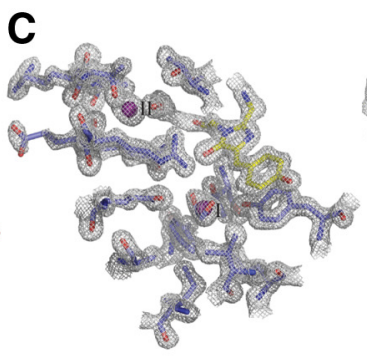

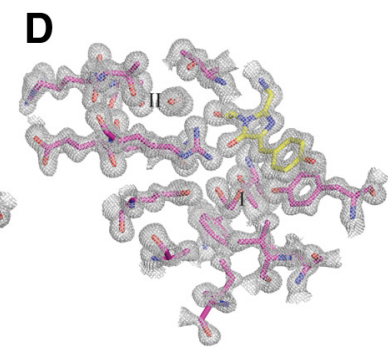

G

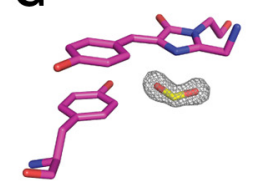

Figure 6. Iodide-binding sites in Q69T/V163A. A, Locations of iodide-binding Sites I (bottom) and II (top). B, Anomalous difference map (4.0 $\sigma$ ) of the iodide-bound structure with the Site I EG removed for visual clarity. The occupancy values were 0.2 (Site I iodide), 0.4 (Site II iodide), and 0.8 (Site I EG). Composite omit maps of the I ${ }^{-}$(purple) complex (C) and apo structure $(\boldsymbol{D})$, both at $1.2 \sigma$. Residues surrounding Sites I $(\boldsymbol{E})$ and II $(\boldsymbol{F})$, superimposing the $\mathrm{I}^{-}$complex (blue), apo protein (magenta), and YFP (light brown; Wachter et al., 2000). Coloring of the bound $\mathrm{I}^{-}$matches its scaffold. EG (yellow) at Site I is shown for the apo protein. $\mathbf{G}$, Composite omit map (1.5 $\sigma$ ) of formate (yellow) in the apo structure with the chromophore and Tyr203.

Table 2. Crystallographic data collection and refinement statistics

\begin{tabular}{|c|c|c|}
\hline & Q69T/V163A аро & Q69T/V163A iodide-bound \\
\hline Space group & $P 2_{1} 2_{1} 2_{1}$ & $P 2_{1} 2_{1} 2_{1}$ \\
\hline \multicolumn{3}{|l|}{ Cell parameters } \\
\hline$a, b, c(\AA)$ & $51.026,62.964,69.078$ & $51.488,63.025,66.070$ \\
\hline \multicolumn{3}{|l|}{ Data collection } \\
\hline Wavelength $(\AA)$ & 1.1109 & 1.1169 \\
\hline Resolution $(\AA)$ & $50.0-1.19(1.21-1.19)$ & $50.0-1.53(1.56-1.53)$ \\
\hline Completeness (\%) & $92.7(55.5)$ & $97.4(94.6)$ \\
\hline Redundancy & $7.4(4.1)$ & $6.8(6.7)$ \\
\hline$R_{\text {sym }}(\%)$ & $4.4(43.2)$ & $5.0(47.2)$ \\
\hline$|/ \sigma|$ & $27.6(2.7)$ & $31.3(4.3)$ \\
\hline \multicolumn{3}{|l|}{ Refinement } \\
\hline Resolution $(\AA)$ & $46.5-1.19$ & $45.6-1.53$ \\
\hline No. reflections & 66756 & 32217 \\
\hline \multicolumn{2}{|l|}{ No. atoms } & $16.0 / 18.3$ \\
\hline Total & 2303 & 2137 \\
\hline Water & 400 & 245 \\
\hline$B$-factors & 20.3 & 19.8 \\
\hline \multicolumn{3}{|l|}{ RMS deviations } \\
\hline Bond lengths $(\AA)$ & 0.008 & 0.012 \\
\hline Bond angles $\left({ }^{\circ}\right)$ & 1.292 & 1.491 \\
\hline PDB code & 3STO & 3 SV5 5 \\
\hline
\end{tabular}

Crystallographic data collection and refinement statistics. Values in parentheses refer to the highest resolution shell. All atoms are included in the $B$-factor calculations.

This sensor had a $\mathrm{Cl}^{-}$affinity of $8.1 \pm 0.5 \mathrm{~mm} . \Delta R_{\max }$ for this version was smaller than for the short linker/S30R version of Clomeleon, but was still approximately twice as large as the value measured for Clomeleon (Fig. 7C). Most importantly, s/n for this variant was substantially larger than that measured for any of the previous versions of Clomeleon (Fig. 7D; $n=21$ ).

In the last step, Clomeleon was further improved by replacing CFP with a brighter donor, Cerulean (Rizzo et al., 2004). This substitution decreased $\Delta R_{\max }$ somewhat (Fig. 7C) but did not affect $\mathrm{Cl}^{-}$affinity. $\mathrm{s} / \mathrm{n}$ for this construct was the best of any of the Clomeleon variants that we produced (Fig. 7D) and is signifi-
Table 3. In vitro chloride binding to fusion proteins

\begin{tabular}{|c|c|c|c|c|c|}
\hline \multicolumn{4}{|c|}{ Fusion protein components } & \multicolumn{2}{|l|}{ In vitro } \\
\hline Donor $^{a}$ & Acceptor & Linker $^{b}$ & $\mathrm{~S} 30 \mathrm{R}^{c}$ & $\Delta R_{\max }$ & $K_{\mathrm{d}}(\mathrm{mm})$ \\
\hline $\mathrm{CFP}^{d}$ & CT & Long & - & 2.68 & $119 \pm 3$ \\
\hline CFP & Q69T/V163A & Long & - & 1.89 & $30.4 \pm 1.0$ \\
\hline Cerulean & Q69T/V163A & Long & - & 1.20 & $23.9 \pm 1.7$ \\
\hline CFP & CT & Long & + & 2.77 & $143 \pm 3$ \\
\hline CFP & Q69T/V163A & Long & + & 1.95 & $28.0 \pm 2.7$ \\
\hline Cerulean & Q69T/V163A & Long & + & 1.26 & $22.6 \pm 2.4$ \\
\hline CFP & $\mathrm{CT}$ & Short & + & 6.48 & $77.9 \pm 1.1$ \\
\hline CFP & Q69T/V163A & Short & + & 4.84 & $23.5 \pm 1.6$ \\
\hline Cerulean $^{e}$ & Q69T/V163A & Short & + & 2.75 & $22.6 \pm 2.2$ \\
\hline
\end{tabular}

In vitro chloride binding to fusion proteins. ${ }^{a} \mathrm{CFP}$ corresponds to the FRET donor in Clomeleon (Kuner and Augustine, 2000). ${ }^{b}$ Constructs with a long linker tested in vitro contained a scrambled protease cleavage site. ${ }^{C}$ The S3OR mutation was in both FPs. ${ }^{d}$ This is the original Clomeleon (Kuner and Augustine, 2000). ${ }^{e}$ SuperClomeleon.

cantly better than that of Clomeleon. We therefore called it SuperClomeleon and next characterized its performance for measuring transient changes in $\left[\mathrm{Cl}^{-}\right]_{\mathrm{i}}$ associated with neuronal inhibition.

\section{Detecting GABA-mediated changes in $\left[\mathrm{Cl}^{-}\right]_{\mathrm{i}}$}

We determined the ability of SuperClomeleon to detect transient $\left[\mathrm{Cl}^{-}\right]_{\mathrm{i}}$ changes produced in neurons by brief applications of the inhibitory neurotransmitter GABA. Cultured hippocampal neurons were transfected with SuperClomeleon and GABA was locally applied from a pipette positioned near the neuron (Fig. $8 A$ ). The neurons were voltage clamped to monitor $\mathrm{Cl}^{-}$flux electrically and to control neuronal membrane potential; introduction of a $5 \mathrm{mM} \mathrm{Cl}^{-}$solution into the cells from the patch pipette maintained resting $\left[\mathrm{Cl}^{-}\right]_{\mathrm{i}}$ near physiological levels (Kuner and Augustine, 2000; Berglund et al., 2006).

A brief (100 ms) application of GABA generated a transient $\mathrm{Cl}^{-}$flux that was observed both as a transmembrane electrical current and as a change in SuperClomeleon FRET (Fig. 8B,C). The magnitude and direction of both current and FRET responses varied with membrane potential according to the direction of $\mathrm{Cl}^{-}$flux. At a holding potential of $-40 \mathrm{mV}, \mathrm{Cl}^{-}$influx 
A
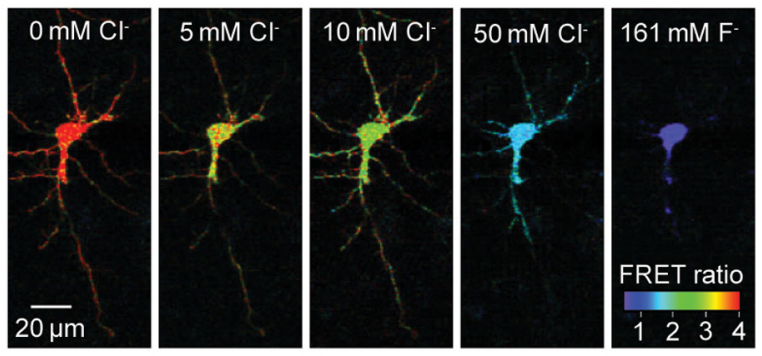

C

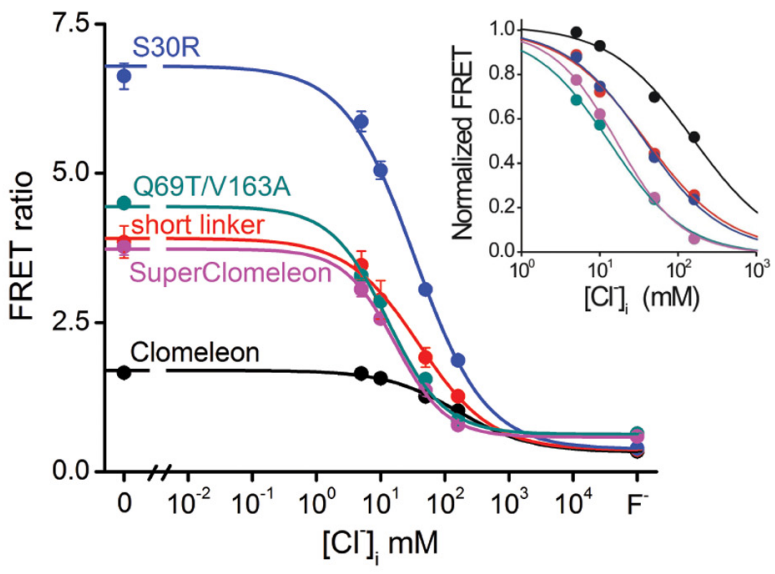

B

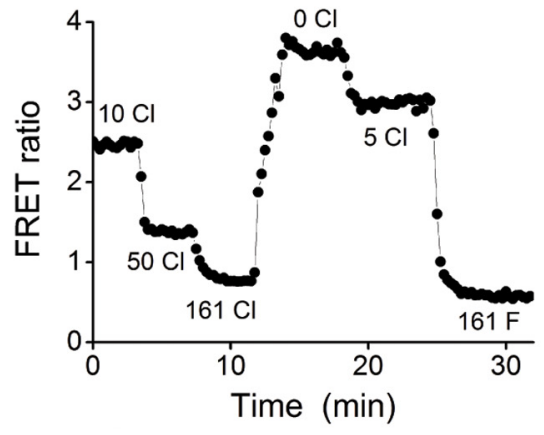

D

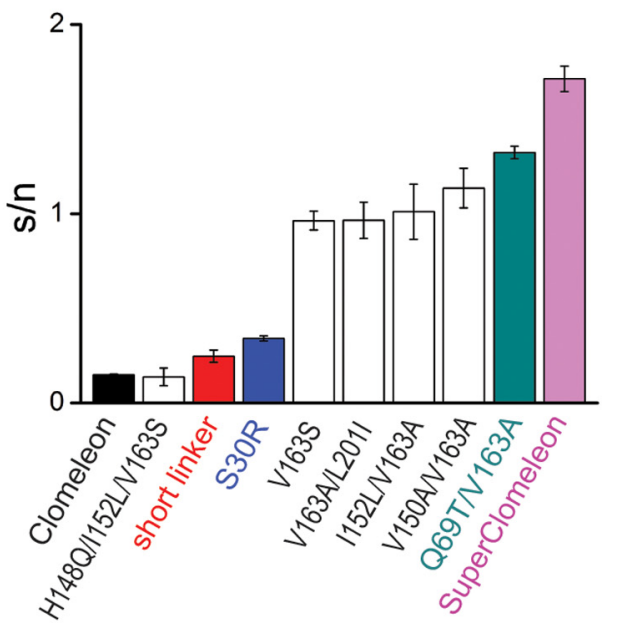

Figure 7. Titration of SuperClomeleon in neurons. $\boldsymbol{A}$, Imaging of $\mathrm{Cl}^{-}$-dependent changes in the FRET ratio (535/485 $\mathrm{nm}$ emission) in a single hippocampal neuron expressing SuperClomeleon. Ionophore treatment was used to clamp $\left[\mathrm{Cl}^{-}\right]_{\mathrm{i}}$ to the values indicated. $\boldsymbol{B}$, Time course of the changes in FRET emission ratio produced in response to changes in $\left[\mathrm{Cl}^{-}\right]_{\mathrm{i}}$ in the cell shown in $\boldsymbol{A}$. C, $\mathrm{Cl}^{-}$titration curves for indicated Clomeleon variants (23 replicates for Clomeleon and $4-21$ replicates for its variants, as described in the text). Curves show fits to Equation. 11, with SEM indicated by error bars. $\mathrm{F}^{-}$indicates FRET values measured in the presence of 161 mm $\mathrm{F}^{-}$. Inset illustrates data normalized by $R_{\text {min }}$ and $R_{\text {max }}$ values, to allow comparison of the relative $\mathrm{Cl}^{-}$affinities of the Clomeleon variants. $\boldsymbol{D}, \mathrm{s} / \mathrm{n}$ estimated from the data shown in $\boldsymbol{C}$. The transformation of Clomeleon into SuperClomeleon consists of the following additive improvements: Clomeleon (black), shorten interdomain linker (red), S30R point mutation in both domains (blue), intermediate affinity-tuning mutations (white), Q69T/V163A double mutant in YFP (teal), and replacement of the CFP domain with Cerulean (magenta). Also shown for comparison is the H1480/I152L/V163S variant (white) described by Markova et al. (2008).

was observed as a large, outward current and a decrease in SuperClomeleon FRET (Fig. 8B, left). At more negative potentials, where the electrochemical driving force on $\mathrm{Cl}^{-}$influx was reduced, the currents and FRET responses became smaller and reversed their polarities at $-90 \mathrm{mV}$ (Fig. $8 B$, right). The reversal potential of approximately $-80 \mathrm{mV}$ was consistent with the $\mathrm{Cl}^{-}$equilibrium potential of $-89 \mathrm{mV}$ predicted by the Nernst equation.

To define the time course and magnitude of the GABAinduced $\mathrm{Cl}^{-}$flux, we integrated the GABA-induced current over time (transmembrane charge). Comparison of the rising phases of the transmembrane charge and the change in SuperClomeleon FRET ratio indicated that the FRET response lags behind the $\mathrm{Cl}^{-}$ flux by $1-2 \mathrm{~s}$ (Fig. 8C). This is consistent with previous observations made with Clomeleon (Kuner and Augustine, 2000). For observations made on the single neuron shown in Figure $8 B$, there was a linear relationship between the $\mathrm{Cl}^{-}$flux, as measured by the charge, and the integrated FRET signal (Fig. 8D). This correlation was also evident in 49 measurements from 10 neurons (Fig. $8 E$, red) and indicates that SuperClomeleon reliably reports the $\mathrm{Cl}^{-}$fluxes and resulting changes in $\left[\mathrm{Cl}^{-}\right]_{\text {i }}$ produced by activation of GABA receptors. Much smaller FRET responses were observed in neurons expressing Clomeleon (Fig. 8E, black). The slope of the relationship between transmembrane charge and integrated FRET signal indicated that SuperClomeleon responses were 4.8-fold greater than those of Clomeleon for a given amount of $\mathrm{Cl}^{-}$flux (Fig. 8E). This indicates that SuperClomeleon improves FRET signal amplitude $\sim 5$-fold compared with Clomeleon. FRET signals declined with time constants of $6.9 \pm 0.6 \mathrm{~s}$ $(n=38)$ for SuperClomeleon and $4.9 \pm 0.7 \mathrm{~s}(n=18)$ for Clomeleon, reflecting slow $\mathrm{Cl}^{-}$efflux from neurons (Kuner and Augustine, 2000; Berglund et al., 2006). By analogy with fluorescent calcium indicators (Regehr and Atluri, 1995), the slower time course of decay observed by SuperClomeleon is probably due to the improved ability of this indicator to detect small and persistent changes in $\left[\mathrm{Cl}^{-}\right]_{\mathrm{i}}$.

\section{Imaging GABA-mediated synaptic inhibition with SuperClomeleon}

One of the potentially most important applications of OSs is imaging the spatiotemporal dynamics of synaptic inhibitory circuits (Mancuso et al., 2011). While Clomeleon is capable of reporting the small changes in $\left[\mathrm{Cl}^{-}\right]_{\mathrm{i}}$ associated with synaptic inhibition (Berglund et al., 2006, 2008), its low $\mathrm{Cl}^{-}$sensitivity and very low $\mathrm{s} / \mathrm{n}$ in the desired concentration range has prevented routine imaging of synaptic inhibition. We therefore evaluated the ability of SuperClomeleon to perform this de- 

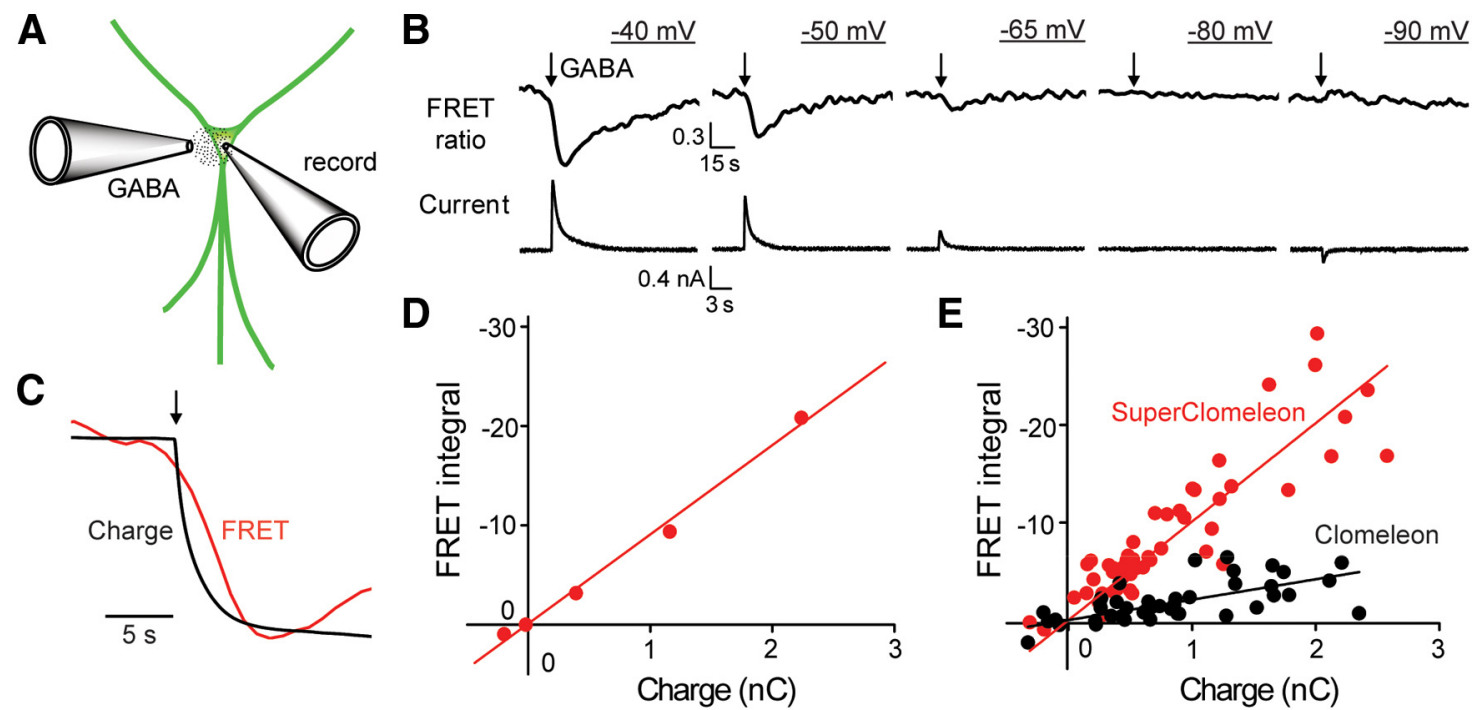

Figure 8. SuperClomeleon monitoring of GABA-induced chloride fluxes. $A$, GABA was locally applied from a pipette (GABA) onto individual neurons that were patch clamped via a second recording pipette (record). B, Simultaneous measurement of GABA-activated $\mathrm{Cl}^{-}$currents (lower) and changes in SuperClomeleon FRET ratio ( $535 / 485 \mathrm{~nm}$ emission; upper) from a single neuron held at various membrane potentials (underlined). GABA application $(100 \mathrm{~ms})$ indicated by arrows. Note different timescales for upper and lower traces. C, Comparison of time course of changes in integrated $\mathrm{Cl}^{-}$current (Charge) and 535/485 nm emission ratio (FRET) in response to GABA application (at arrow), measured at a holding potential of $-50 \mathrm{mV}$. Traces have been normalized (and inverted, for the case of charge) to allow a comparison of their kinetics. D, Relationship between GABA-induced changes in integrated $\mathrm{Cl}^{-}{ }^{-}$currents (Charge) and FRET signals for $\boldsymbol{B}$. $\boldsymbol{E}$, Aggregate data for cells expressing either SuperClomeleon (red, 10 cells) or Clomeleon (black, 7 cells). Lines indicate linear regression fit to the data, with slopes of $10.1 \pm 0.5$ (SEM) $s \cdot \mathrm{nC}{ }^{-1}$ for SuperClomeleon and $2.1 \pm 0.2 \mathrm{~s} \cdot \mathrm{nC}^{-1}$ for Clomeleon. Units for $y$-axes (integrated FRET signals) in $\boldsymbol{D}$ and $\boldsymbol{E}$ are seconds.

manding task in cultured hippocampal neurons by activating inhibitory synapses via electrical stimulation of nearby interneurons (Fig. 9A).

Postsynaptic neurons expressing Clomeleon or SuperClomeleon were voltage clamped $(-50 \mathrm{mV})$ to measure the postsynaptic $\mathrm{Cl}^{-}$currents associated with IPSCs. Under these conditions, brief trains of electrical stimuli produced IPSCs, which decreased during the train (Fig. 9B, bottom) due to synaptic depression (Gitler et al., 2004b). In neurons expressing Clomeleon, inhibitory synaptic activity rarely produced detectable FRET changes (Fig. 9B, left). However, similar stimuli reliably produced transient reductions in SuperClomeleon FRET (Fig. 9B, right), revealing that this indicator is capable of detecting the relatively small changes in $\left[\mathrm{Cl}^{-}\right]_{\mathrm{i}}$ associated with synaptic inhibition. To compare the performance of the two OSs, we measured synaptic responses in eight cells expressing SuperClomeleon and in five cells expressing Clomeleon. While 100\% (16/16) of the trials yielded detectable SuperClomeleon responses, Clomeleon reported responses only $50 \%(8 / 16)$ of the time.

Responses to inhibitory synaptic activity were quantified to provide a direct comparison of $s / n$ for inhibitory synaptic responses reported by SuperClomeleon and Clomeleon. For the examples shown in Figure $9 B$, the $s / n$ ratio was $\sim 5.8$ for the neuron expressing SuperClomeleon and was too small to be determined reliably in the neuron expressing Clomeleon. This was further quantified by first calculating the $\mathrm{s} / \mathrm{n}$ by integrating the stimulus-induced change in FRET signal and dividing this value by the baseline FRET noise (as done in Fig. 8D). Because of substantial cell-to-cell variations in IPSC amplitude, these responses were then normalized for the amount of synaptic $\mathrm{Cl}^{-}$flux by dividing their values by the synaptic charge produced by the stimulus. The cumulative probability plots shown in Figure $9 C$ show the results of this analysis, with the dashed vertical line indicating values where there was no measurable response (i.e., a s/n of 0 ). This analysis revealed that, on average, the $s / n$ of SuperClome- leon responses $\left(\right.$ median $=0.15 \pm 0.01 \mathrm{~s} \cdot \mathrm{pC}^{-1}$ ) was 5.4 -fold larger than those of Clomeleon (median $=0.028 \pm 0.008$ $\left.\mathrm{s} \cdot \mathrm{pC}^{-1}\right)$.

For many potential applications of SuperClomeleon, it is likely that the postsynaptic neuron would not be voltage clamped. Indeed, in many applications it is possible that there would be no electrophysiological measurements of postsynaptic activity at all. FRET responses should be smaller when the neurons are not voltage clamped, because the electrochemical driving force on $\mathrm{Cl}^{-}$will change as the membrane potential changes during the IPSP. Thus, we completed our analysis by comparing the ability of SuperClomeleon and Clomeleon to detect inhibitory activity in postsynaptic neurons that were not voltage clamped.

Under current-clamp conditions, the same brief trains of inhibitory synaptic activity produced a series of IPSPs (Fig. $9 D$, bottom). In neurons expressing Clomeleon, detectable FRET signals were observed in only three of nine experiments (Fig. 9D, left). In contrast, a similar amount of inhibitory synaptic activity produced detectable changes in FRET in every case (nine of nine experiments) for neurons expressing SuperClomeleon (Fig. 9D, right). The mean integrated change in FRET signal measured with SuperClomeleon was 5.4-fold larger than for the integrated change in FRET signal measured in neurons expressing Clomeleon (Fig. 9E). The difference in the performance of Clomeleon and SuperClomeleon for detecting changes in $\left[\mathrm{Cl}^{-}\right]_{\mathrm{i}}$ associated with IPSPs was even greater when considering $s / n$, rather than integrated change in FRET signal: the $\mathrm{s} / \mathrm{n}$ for SuperClomeleon was $>6$ times larger than that measured for Clomeleon (Fig. 9F). In summary, our measurements under both voltage-clamp and current-clamp conditions indicate that the $s / \mathrm{n}$ was $\sim 6$-fold better for SuperClomeleon than for Clomeleon. We therefore conclude that SuperClomeleon is superior for measurements of changes in $\left[\mathrm{Cl}^{-}\right]_{\mathrm{i}}$ associated with synaptic inhibition. 
A
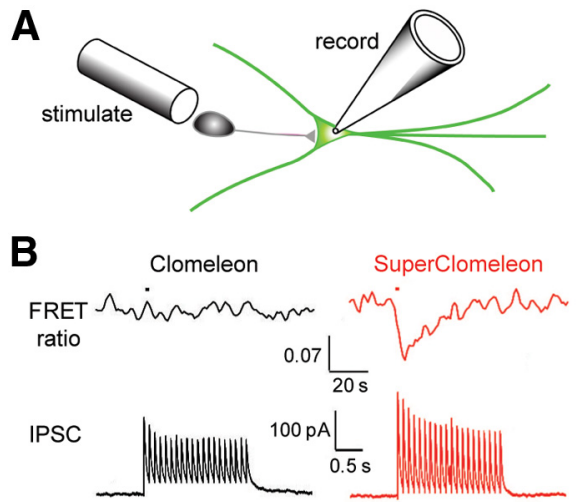

D

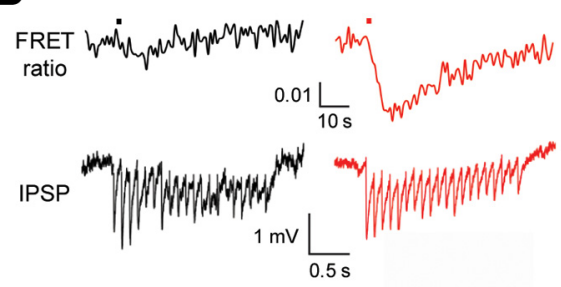

C

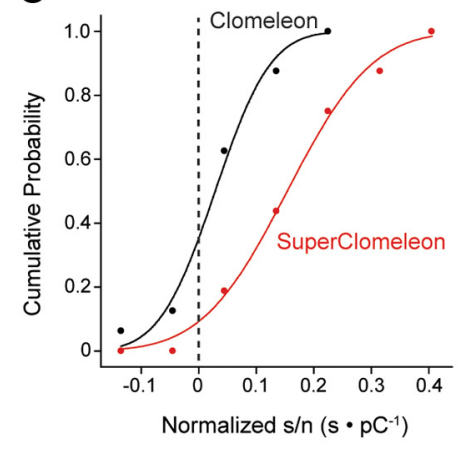

E

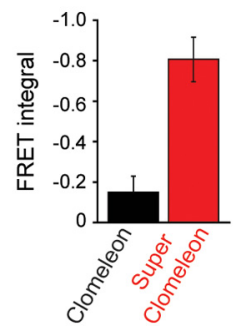

$\mathbf{F}$

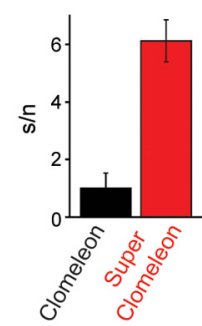

Figure 9. Imaging synaptic inhibition with SuperClomeleon. $A$, A presynaptic inhibitory neuron was stimulated by an extracellular electrode (stimulate), while a postsynaptic neuron expressing SuperClomeleon was patch clamped via a recording pipette (record). $\boldsymbol{B}$, A brief train of electrical stimuli $(10 \mathrm{~Hz}, 2 \mathrm{~s})$ applied to the inhibitory neuron produced IPSCs (lower) and changes in FRET ratio (535/485 nm emission, upper) in voltage clamped ( $-50 \mathrm{mV}$ ) postsynaptic neurons expressing either Clomeleon (black) or SuperClomeleon (red). Note different timescales for upper and lower traces. Four FRET signal trials were averaged in an effort to extract a detectable signal from the Clomeleon-expressing neuron; for comparison purposes, the same was done for the SuperClomeleon responses. These examples were chosen because they had similar synaptic charge (integral of IPSCs) in response to the stimuli. C, s/n characteristics for FRET ratio changes resulting from inhibitory synaptic activity. Response s/n characteristics were quantified by integrating the stimulus-induced change in FRET signal (signal) produced by either Clomeleon (black) or SuperClomeleon (red) and dividing this by the baseline FRET noise. These responses were then normalized by dividing them by the synaptic charge produced by the stimulus, accounting for cell-to-cell variations in IPSCs. Individual measurements $(n=16$ for each indicator) were then binned into groups to form the cumulative distributions, which were fit by Gaussian functions (smooth curves). Dashed line indicates $s / n=0$; i.e., no signal. D, IPSPs (lower) and changes in FRET ratio (535/485 nm emission, upper) measured in response to a brief train of electrical stimuli $(10 \mathrm{~Hz}, 2 \mathrm{~s})$ in neurons not under voltage clamp. Black traces come from a neuron expressing Clomeleon (black), while red traces are from a neuron expressing SuperClomeleon. $\boldsymbol{E}$, Mean values for integrated change in FRET signal, or $\mathrm{s} / \mathrm{n}(\boldsymbol{F})$, measured in response to IPSPs in neurons expressing Clomeleon or SuperClomeleon $(n=$ 9 cells for each). Error bars indicate SEM.

\section{Discussion}

We used a multistage strategy to improve $\mathrm{Cl}^{-}$sensing by Clomeleon. First, using a cell-free automation methodology to rapidly prototype variants in vitro, we improved YFP by more closely matching its $\mathrm{Cl}^{-}$affinity to postsynaptic $\left[\mathrm{Cl}^{-}\right]_{\mathrm{i}}$. Next, we incorporated this affinity-tuned single domain into Clomeleon for FRET-based sensing, enhancing $s / n$ in cellular imaging experiments. Improvements in affinity matching, while retaining fluorescence, resulted in the largest enhancement of cellular imaging performance. Shortening the interdomain linker and introducing brightening mutations significantly improved the FRET response. This process culminated in identification of SuperClomeleon, a variant that greatly enhanced observation of synaptic inhibition in neurons.

Choosing single-point mutants with clearly improved $\rho_{5.5}$ values was a critical step for success; incremental improvements also arose from combinations of initially suboptimal variants. Nevertheless, given that the number of variants that need to be examined in an enumerative strategy can increase approximately exponentially with each iteration that includes more positions, carrying forward only clearly improved variants balances experimental load and likelihood of success. We

observed good agreement between the affinities determined in the initial screen and the proteins produced conventionally. Cell-free protein engineering therefore is a powerful tool for generating and prototyping mutant proteins.

Our structural analysis revealed that the effects of the mutations are complex. The halide-binding site of SuperClomeleon resides within the internal cavity that accommodates the conformational change required for chromophore cyclization (Barondeau et al., 2003). This internal cavity accommodates two halide-binding sites, as well as a molecule of EG and a molecule of formate. The appearance of a second halidebinding site accompanied by motions of the hydrogen-bonding side chains in the otherwise rigid structure shows that the lining of this cavity is mobile and can accommodate binding sites through subtle rearrangements. The presence of small organics, such as ethylene glycol and formate, suggests that this cavity can be further diversified to bind and detect small molecules.

The YFP chromophore exists in four possible charge states (anionic, cationic, zwitterionic, and neutral), of which only the anionic form is fluorescent (Elsliger et al., 1999). Bound $\mathrm{Cl}^{-}$and the anionic chromophore interact unfavorably by electrostatic repulsion, so that $\mathrm{Cl}^{-}$binding is favored in the protonated, neutral, nonfluorescent state. These interactions link $\left[\mathrm{Cl}^{-}\right]$and affinity with $\mathrm{pH}$ and chromophore $\mathrm{p} K_{\mathrm{a}}$, setting up a trade-off between $\mathrm{Cl}^{-}$affinity and sensor brightness. Improvements in $\mathrm{Cl}^{-}$affinity correlate with raised chromophore $\mathrm{p} K_{\mathrm{a}}$ values relative to CT, which decreases the concentration of anionic chromophore in the halide-free protein at a given $\mathrm{pH}$, thereby diminishing sensor brightness. This decreased fluorescence reduces $\Delta F_{\max }$ because $\mathrm{Cl}^{-}$binding quenches emission. The highest affinity variant $\mathrm{Q} 183 \mathrm{~A}$ has a raised $\mathrm{p} K_{\mathrm{a}}$ value and diminished fluorescence brightness. Similarly, other mutations, including $\mathrm{H} 148 \mathrm{Q}$, increase affinity at the expense of brightness (Jayaraman et al., 2000; Wachter et al., 2000; Galietta et al., 2001; Markova et al., 2008;Fig. 3 A, B). In constructing SuperClomeleon these trade-offs could be balanced sufficiently to improve sensing substantially; that is, SuperClomeleon offers improved sensitivity to physiological $\mathrm{Cl}^{-}$fluxes despite a higher interference by protons.

Affinity matching together with other enhancements improved the $s / n$ characteristics of SuperClomeleon in cellular imaging. As a result, SuperClomeleon represents a significant improvement over Clomeleon and consistently outperformed Clomeleon in all of our neuronal imaging experiments: $\mathrm{Cl}^{-}$titrations, activation of GABA receptors via exogenous GABA, and electrically evoked synaptic inhibition. Quantitatively, our GABA application experiments indicate a 4.8-fold improvement in signal for SuperClomeleon relative to Clomeleon, while the synaptic inhibition data indicate a $\mathrm{s} / \mathrm{n}$ that is 5 - to 6 -fold larger than that 
measured for Clomeleon. The key qualitative improvement is that SuperClomeleon robustly detects inhibitory synaptic activity in single neurons even under the relatively noisy conditions of two-photon imaging; this was not the case for Clomeleon (Berglund et al., 2006, 2008). Of particular note is that SuperClomeleon can detect responses to brief IPSP trains, an advantage that will prove useful for many future applications and will enable optogenetic imaging of the spatiotemporal dynamics of synaptic inhibitory circuits at the cellular level of resolution (Mancuso et al., 2011).

In conclusion, we have partnered automated in vitro protein engineering technology with cellular imaging to develop an OS with improved ability to image inhibitory synaptic activity. This development not only enables novel brain imaging experiments but also establishes a general approach for developing and improving many other types of OSs.

\section{References}

Adams PD, Afonine PV, Bunkóczi G, Chen VB, Davis IW, Echols N, Headd JJ, Hung LW, Kapral GJ, Grosse-Kunstleve RW, McCoy AJ, Moriarty NW, Oeffner R, Read RJ, Richardson DC, Richardson JS, Terwilliger TC, Zwart PH (2010) PHENIX: a comprehensive Pythonbased system for macromolecular structure solution. Acta Cryst D 66:213-221. CrossRef

Allert M, Cox JC, Hellinga HW (2010) Multifactorial determinants of protein expression in prokaryotic open reading frames. J Mol Biol 402:905918. CrossRef Medline

Arosio D, Garau G, Ricci F, Marchetti L, Bizzarri R, Nifosì R, Beltram F (2007) Spectroscopic and structural study of proton and halide ion cooperative binding to GFP. Biophys J 93:232-244. CrossRef Medline

Arosio D, Ricci F, Marchetti L, Gualdani R, Albertazzi L, Beltram F (2010) Simultaneous intracellular chloride and $\mathrm{pH}$ measurements using a GFPbased sensor. Nat Methods 7:516-518. CrossRef Medline

Barondeau DP, Putnam CD, Kassmann CJ, Tainer JA, Getzoff ED (2003) Mechanism and energetics of green fluorescent protein chromophore synthesis revealed by trapped intermediate structures. Proc Natl Acad Sci U S A 100:12111-12116. CrossRef Medline

Berglund K, Schleich W, Krieger P, Loo LS, Wang D, Cant NB, Feng G, Augustine GJ, Kuner T (2006) Imaging synaptic inhibition in transgenic mice expressing the chloride indicator, Clomeleon. Brain Cell Biol 35: 207-228. CrossRef Medline

Berglund K, Schleich W, Wang H, Feng G, Hall WC, Kuner T, Augustine GJ (2008) Imaging synaptic inhibition through the brain via genetically targeted Clomeleon. Brain Cell Biol 36:101-118. CrossRef Medline

Bright GR, Fisher GW, Rogowska J, Taylor DL (1989) Fluorescence imaging microscopy. Methods Cell Biol 30:157-192. CrossRef Medline

Cox JC, Lape J, Sayed MA, Hellinga HW (2007) Protein fabrication automation. Protein Sci 16:379-390. CrossRef Medline

Dickson RM, Cubitt AB, Tsien RY, Moerner WE (1997) On/off blinking and switching behaviour of single molecules of green fluorescent protein. Nature 388:355-358. CrossRef Medline

Elsliger MA, Wachter RM, Hanson GT, Kallio K, Remington SJ (1999) Structural and spectral response of green fluorescent protein variants to changes in pH. Biochemistry 38:5296-5301. CrossRef Medline

Emsley P, Cowtan K (2004) Coot: model-building tools for molecular graphics. Acta Crystallogr D Biol Crystallogr 60:2126-2132. CrossRef Medline

Evers TH, van Dongen EM, Faesen AC, Meijer EW, Merkx M (2006) Quantitative understanding of the energy transfer between fluorescent proteins connected via flexible peptide linkers. Biochemistry 45:13183-13192. CrossRef Medline

Flach J, Bossie M, Vogel J, Corbett A, Jinks T, Willins DA, Silver PA (1994) A yeast RNA-binding protein shuttles between the nucleus and the cytoplasm. Mol Cell Biol 14:8399-8407. Medline

Galietta LJ, Haggie PM, Verkman AS (2001) Green fluorescent proteinbased halide indicators with improved chloride and iodide affinities. FEBS Lett 499:220-224. CrossRef Medline

Gitler D, Takagishi Y, Feng J, Ren Y, Rodriguiz RM, Wetsel WC, Greengard P, Augustine GJ (2004a) Different presynaptic roles of synapsins at excit- atory and inhibitory synapses. J Neurosci 24:11368-11380. CrossRef Medline

Gitler D, Xu Y, Kao HT, Lin D, Lim S, Feng J, Greengard P, Augustine G) (2004b) Molecular determinants of synapsin targeting to presynaptic terminals. J Neurosci 24:3711-3720. CrossRef Medline

Griesbeck O, Baird GS, Campbell RE, Zacharias DA, Tsien RY (2001) Reducing the environmental sensitivity of yellow fluorescent protein. J Biol Chem 276:29188-29194. CrossRef Medline

Grynkiewicz G, Poenie M, Tsien RY (1985) A new generation of Ca2+ indicators with greatly improved fluorescence properties. J Biol Chem 260: 3440-3450. Medline

Heim R, Prasher DC, Tsien RY (1994) Wavelength mutations and posttranslational autoxidation of green fluorescent protein. Proc Natl Acad Sci U S A 91:12501-12504. CrossRef Medline

Hires SA, Zhu Y, Tsien RY (2008) Optical measurement of synaptic glutamate spillover and reuptake by linker optimized glutamate-sensitive fluorescent reporters. Proc Natl Acad Sci U S A 105:4411-4416. CrossRef Medline

Isom DG, Vardy E, Oas TG, Hellinga HW (2010) Picomole-scale characterization of protein stability and function by quantitative cysteine reactivity. Proc Natl Acad Sci U S A 107:4908-4913. CrossRef Medline

Jayaraman S, Haggie P, Wachter RM, Remington SJ, Verkman AS (2000) Mechanism and cellular applications of a green fluorescent protein-based halide sensor. J Biol Chem 275:6047-6050. CrossRef Medline

Kuner T, Augustine GJ (2000) A genetically encoded ratiometric indicator for chloride: capturing chloride transients in cultured hippocampal neurons. Neuron 27:447-459. CrossRef Medline

Layton CJ, Hellinga HW (2010) Thermodynamic analysis of ligandinduced changes in protein thermal unfolding applied to highthroughput determination of ligand-affinities with extrinsic fluorescent dyes. Biochemistry 49:10831-10841. CrossRef Medline

Mancuso JJ, Kim J, Lee S, Tsuda S, Chow NB, Augustine GJ (2011) Optogenetic probing of functional brain circuitry. Exp Physiol 96:26-33. Medline

Markova O, Mukhtarov M, Real E, Jacob Y, Bregestovski P (2008) Genetically encoded chloride indicator with improved sensitivity. J Neurosci Methods 170:67-76. CrossRef Medline

Marvin JS, Corcoran EE, Hattangadi NA, Zhang JV, Gere SA, Hellinga HW (1997) The rational design of allosteric interactions in a monomeric protein and its application to the construction of biosensors. Proc Natl Acad Sci U S A 94:4366-4371. CrossRef Medline

McCoy AJ, Grosse-Kunstleve RW, Adams PD, Winn MD, Storoni LC, Read RJ (2007) Phaser crystallographic software. J Appl Crystallogr 40:658674. CrossRef Medline

Miyawaki A (2005) Innovations in the imaging of brain functions using fluorescent proteins. Neuron 48:189-199. CrossRef Medline

Miyawaki A, Llopis J, Heim R, McCaffery JM, Adams JA, Ikura M, Tsien RY (1997) Fluorescent indicators for $\mathrm{Ca}^{2+}$ based on green fluorescent proteins and calmodulin. Nature 388:882-887. CrossRef Medline

Murshudov GN, Vagin AA, Dodson EJ (1997) Refinement of macromolecular structures by the maximum-likelihood method. Acta Crystallogr D Biol Crystallogr 53:240-255. CrossRef Medline

Okumoto S (2010) Imaging approach for monitoring cellular metabolites and ions using genetically encoded biosensors. Curr Opin Biotechnol 21:45-54. CrossRef Medline

Okumoto S, Looger LL, Micheva KD, Reimer RJ, Smith SJ, Frommer WB (2005) Detection of glutamate release from neurons by genetically encoded surface-displayed FRET nanosensors. Proc Natl Acad Sci U S A 102:8740-8745. CrossRef Medline

Otwinowski Z, Minor W (1997) Processing of X-ray diffraction data collected in oscillation mode. Methods Enzymol 276:307-326. CrossRef

Pédelacq JD, Cabantous S, Tran T, Terwilliger TC, Waldo GS (2006) Engineering and characterization of a superfolder fluorescent protein. Nat Biotechnol 24:79-88. CrossRef Medline

Press WH, Teukolsky SA, Vetterling WT, Flannery BP (2007) Numerical recipes: the art of scientific computing, Ed 3. New York: Cambridge UP.

Regehr WG, Atluri PP (1995) Calcium transients in cerebellar granule cell presynaptic terminals. Biophys J 68:2156-2170. CrossRef Medline

Rizzo MA, Springer GH, Granada B, Piston DW (2004) An improved cyan fluorescent protein variants useful for FRET. Nat Biotechnol 22:445-449. CrossRef Medline 
Shimozono S, Hosoi H, Mizuno H, Fukano T, Tahara T, Miyawaki A (2006) Concatenation of cyan and yellow fluorescent proteins for efficient resonance energy transfer. Biochemistry 45:6267-6271. CrossRef Medline

Siegel MS, Isacoff EY (1997) A genetically encoded optical probe of membrane voltage. Neuron 19:735-741. CrossRef Medline

Sniegowski JA, Lappe JW, Patel HN, Huffman HA, Wachter RM (2005) Base catalysis of chromophore formation in Arg96 and Glu222 variants of green fluorescent protein. J Biol Chem 280:26248-26255. CrossRef Medline

Studier FW (2005) Protein production by auto-induction in highdensity shaking cultures. Protein Expr Purif 41:207-234. CrossRef Medline

Wachter RM, Remington SJ (1999) Sensitivity of the yellow fluorescent protein to halides and nitrate. Curr Biol 9:R628-R629. CrossRef Medline

Wachter RM, Yarbrough D, Kallio K, Remington SJ (2000) Crystallographic and energetic analysis of binding of selected anions to the yellow variants of green fluorescent protein. J Mol Biol 301:157-171. CrossRef Medline

Xia Z, Zhou Q, Lin J, Liu Y (2001) Stable SNARE complex prior to evoked synaptic vesicle fusion revealed by fluorescence resonance energy transfer. J Biol Chem 276:1766-1771. Medline

Zhang F, Gradinaru V, Adamantidis AR, Durand R, Airan RD, de Lecea L, Deisseroth K (2010) Optogenetic interrogation of neural circuits: technology for probing mammalian brain structures. Nat Protoc 5:439-456. CrossRef Medline 